\title{
Analytical Model for Predesigning Probe-Fed Hybrid Microstrip Antennas
}

\author{
Nilson R. Rabelo, ${ }^{1}$ J. C. da S. Lacava, ${ }^{1}$ Alexis F. Tinoco Salazar ${ }^{D},{ }^{2}$ P. C. Ribeiro Filho, ${ }^{1}$ \\ D. C. Nascimento, ${ }^{1}$ Rubén D. León Vásquez, ${ }^{2}$ and Sidnei J. S. Sant'Anna ${ }^{3}$ \\ ${ }^{1}$ Laboratório de Antenas e Propagação (LAP), Instituto Tecnológico de Aeronáutica (ITA), Praça Mal. Eduardo Gomes 50, \\ 12228-900 São José dos Campos, SP, Brazil \\ ${ }^{2}$ Departamento de Eléctrica y Electrónica (DEE), Centro de Investigaciones Científicas y Tecnológicas del Ejército (CICTE), \\ Universidad de las Fuerzas Armadas (ESPE), Av. General Rumiñahui s/n, Sangolquí, Ecuador \\ ${ }^{3}$ Divisão de Processamento de Imagem (DPI), Instituto Nacional de Pesquisas Espaciais (INPE), Av. Dos Astronautas 1758, \\ 12227-010 São José dos Campos, SP, Brazil
}

Correspondence should be addressed to Alexis F. Tinoco Salazar; aftinoco@espe.edu.ec

Received 13 September 2017; Accepted 5 December 2017; Published 28 February 2018

Academic Editor: Miguel Ferrando Bataller

Copyright (C) 2018 Nilson R. Rabelo et al. This is an open access article distributed under the Creative Commons Attribution License, which permits unrestricted use, distribution, and reproduction in any medium, provided the original work is properly cited.

\begin{abstract}
Based on the equivalent resonant cavity model, an effective analysis methodology of probe-fed hybrid microstrip antennas is carried out in this paper, resulting in a better understanding of the parameter interrelations affecting their behavior. With that, a new design criterion focused on establishing uniform radiation patterns with balanced $3 \mathrm{~dB}$ angles is proposed and implemented. Results obtained with the proposed model closely matched HFSS simulations. Measurements made on a prototype antenna, manufactured with substrate integrated waveguide (SIW) technology, also showed excellent agreement, thus validating the use of the cavity model for predesigning hybrid microstrip antennas in a simple, visible, and time- and cost-effective way.
\end{abstract}

\section{Introduction}

Microstrip antennas and arrays can be accurately designed using modern electromagnetic simulators such as CST [1] and HFSS [2]. However, as their focus is on analysis, the development process becomes more simple and time- and cost-effective when the geometry under study is predesigned in the first place. In this context, to predesign means the determination of preliminary antenna dimensions before implementation in the simulators. Once in the software environment-which incorporates significant effects, such as dielectric and ground plane truncation, that are not taken into account in more basic models-the antenna can then be more comprehensively analyzed and its dimensions optimized to meet project specifications. Naturally, the closer the predesigned dimensions are to the optimal ones, the faster the analysis-synthesis process will converge.
Although Deschamps [3] proposed the concept of microstrip radiators back in 1953, it was only in the 1970s, with the production of low-loss microwave laminates that this type of antenna started gained popularity [4] and a number of practical applications came about [5]. Nowadays, their peculiar characteristics are established [6-8] and they are found as customary components in modern communication systems [9]. Analytical methods, such as the transmission line [10], resonant cavity [11], and electric surface current [12] models, have been extensively used for predesigning planar, cylindrical, and spherical microstrip antennas [6-8, 13-15].

The conventional probe-fed linearly polarized antenna, comprising a metallic rectangular patch printed on top of a grounded planar dielectric layer, is certainly the most popular microstrip radiator [16], but at the cost of high levels of cross-polarization in the $\mathrm{H}$ plane, as recently revisited [5]. A convenient way to overcome this limitation consists of 


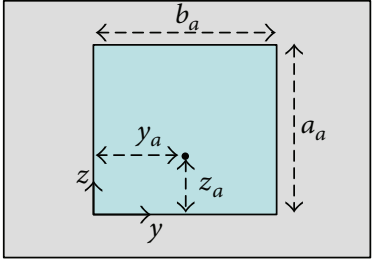

(a)

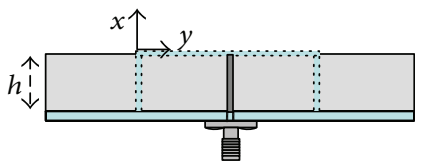

(b)

FIgURE 1: Hybrid microstrip antenna: (a) top view and (b) lateral view.

using a hybrid microstrip patch, as described in [9, 16-21]. In this publication, hybrid microstrip antennas fed by a coaxial probe are predesigned via the cavity model. Although this model had been previously utilized [9, 16, 18, 22, 23], the systematic determination of adequate design criteria has not been fully carried out yet. Such is the primary goal of this work.

To validate our predesigning procedure, HFSS simulations were run, and excellent agreement with our results confirms the effectiveness of the equivalent resonant cavity model for thin hybrid antennas. Since the implementation of vertical electric walls in microstrip structures is not straightforward, a prototype antenna was manufactured using the substrate integrated waveguide (SIW) technique [24]. Here again, an excellent match between predesigned and experimental results was observed.

\section{Cavity Model}

Differently, from their conventional counterpart, hybrid microstrip antennas fed by coaxial probes can exhibit low cross-polarization level in the $\mathrm{H}$ plane, as recently reported in $[9,16-19,25,26]$. That outstanding behavior is obtained by connecting two opposite edges of a rectangular patch to the antenna ground plane. The typical geometry, proposed by Penard and Daniel [23], is shown in Figure 1, where $a_{a}$ and $b_{a}$ denote the patch dimensions and $h$ is the thickness of the substrate, $\varepsilon$ of electric permittivity, and $\mu_{0}$ of magnetic permeability. Note the antenna is fed, at coordinates $y_{a}$ and $z_{a}$, by a SMA (subminiature version A) connector whose characteristic impedance is $50 \Omega$.

The resonant cavity model, used for the analysis of conventional microstrip radiators [11], is applied here to the hybrid antenna. In this model, the region between the patch and the ground plane is considered equivalent to a cavity made up of electric walls at $x=0, x=-h, y=0$, and $y=b$ and magnetic walls at $z=0$ and $z=a$, as illustrated in Figure 2. The equivalent cavity dimension along the $z$-axis shall be made greater than the actual antenna dimension (i.e., $a>a_{a}$ ) to account for the fringing effect at the edges [10]. On the other hand, since the walls at $y=0$ and $y=b$

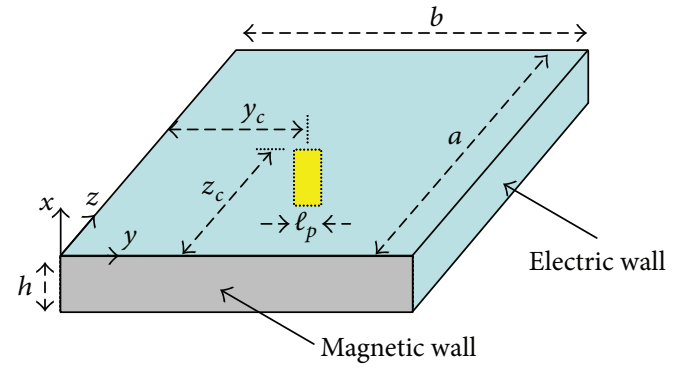

FIgURE 2: Equivalent cavity excited by a strip of uniform current density.

are electrically grounded to the bottom wall, the dimensions along the $y$-axis of the equivalent cavity and the actual antenna are the same (i.e., $b_{a}=b$ ).

By modeling the coaxial feeder by a vertical strip of uniform current density,

$$
\begin{aligned}
& \vec{J}_{f}=J(y) \delta\left(z-z_{c}\right) \hat{x}, \\
& J(y)= \begin{cases}J_{0}, & \text { if }\left(\frac{y_{c}-\ell_{p}}{2} \leq y \leq \frac{y_{c}+\ell_{p}}{2}\right), \\
0, & \text { otherwise, }\end{cases}
\end{aligned}
$$

located at the point $\left(y_{c}, z_{c}\right)$; as illustrated in Figure 2, the electric field amplitude of the resonant mode $\{m, n\}$ inside the cavity is given by

$$
E_{m n}=\frac{i 2 \omega \mu_{0} I_{0} \xi_{n}}{a b\left(k^{2}-k_{m n}^{2}\right)} \sin \left(k_{y} y_{c}\right) \cos \left(k_{z} z_{c}\right) \operatorname{sinc}\left(\frac{m \pi \ell_{p}}{2 b}\right),
$$

where

$$
\begin{aligned}
k^{2} & =\omega^{2} \mu_{0} \varepsilon, \\
k_{m n}^{2} & =k_{y}^{2}+k_{z}^{2}=\left(\frac{m \pi}{b}\right)^{2}+\left(\frac{n \pi}{a}\right)^{2},
\end{aligned}
$$

with $m=1,2,3, \ldots,(m \neq 0)$ and $n=0,1,2,3, \ldots, \xi_{n}=1$ if $n=0$ and $\xi_{n}=2$ if $n \neq 0, \omega$ is the angular frequency and $I_{0}=J_{0} \ell_{p}$ is the current on the feeding strip.

Therefore, the total electric field inside the resonant cavity excited by a uniform current density strip is given by the following expression:

$$
\vec{E}=i \omega \mu_{0} \sum_{m} \sum_{n} \frac{T_{m n}}{\left(k^{2}-k_{m n}^{2}\right)} \sin \left(\frac{m \pi y}{b}\right) \cos \left(\frac{n \pi z}{a}\right) \hat{x},
$$

where

$$
T_{m n}=\frac{2 I_{0} \xi_{n}}{a b} \sin \left(\frac{m \pi y_{c}}{b}\right) \cos \left(\frac{n \pi z_{c}}{a}\right) \operatorname{sinc}\left(\frac{m \pi \ell_{p}}{2 b}\right) .
$$

Consequently, the cavity input impedance becomes

$$
\begin{aligned}
Z_{\text {in }}= & \frac{i 2 h \omega \mu_{0}}{a b} \sum_{m} \sum_{n} \frac{\xi_{n}}{\left(k_{m n}^{2}-k^{2}\right)} \\
& \times \sin ^{2}\left(\frac{m \pi y_{c}}{b}\right) \cos ^{2}\left(\frac{n \pi z_{c}}{a}\right) \operatorname{sinc}^{2}\left(\frac{m \pi \ell_{p}}{2 b}\right) .
\end{aligned}
$$


However, this equation does not properly describe the input impedance of a microstrip antenna. According to [11], more accurate results are obtained if the cavity wavenumber $k$ is replaced with the effective wavenumber $k_{\mathrm{ef}_{m n}}$, given by

$$
k_{\mathrm{ef}_{m n}}^{2}=\left(1-i \tan \theta_{\mathrm{ef}_{m n}}\right) k^{2}
$$

where

$$
\begin{aligned}
& \tan \theta_{\mathrm{ef}_{m n}}=\tan \theta+\frac{\delta_{m n}}{h b}\left\{\frac{(2 h+b) a^{2} m^{2}+b^{3} n^{2}}{a^{2} m^{2}+b^{2} n^{2}}\right\} \\
& +\frac{m^{2} \omega_{m n} \mu_{0} h b \xi_{n}}{2 \varepsilon_{r} a \eta_{0}} I_{\mathrm{int}}, \quad \delta_{m n}=\sqrt{\frac{2}{\left(\omega_{m n} \mu_{0} \sigma\right)}}, \\
& I_{\text {int }}=\int_{-(\pi / 2)}^{\pi / 2} \int_{0}^{\pi} \mid\left\{\frac{\cos (m \pi) e^{i k_{0} b \sin \theta \sin \phi}-1}{\left(k_{0} b \sin \theta \operatorname{sen} \phi\right)^{2}-(m \pi)^{2}}\right\} \\
& \left.\cdot\left\{\cos (n \pi) e^{i k_{0} a \cos \theta}-1\right\}\right|^{2} \\
& \times\left(\cos ^{2} \phi+\sin ^{2} \phi \cos ^{2} \theta\right) \sin \theta d \theta d \phi, \\
& k_{0}=\omega \sqrt{\mu_{0} \varepsilon_{0}},
\end{aligned}
$$

with $\tan \theta_{\mathrm{ef}_{m n}}$ denoting the effective loss tangent, $\tan \theta$ the loss tangent of the substrate, $\sigma$ the electrical conductivity of the cavity electric walls, $\delta_{m n}$ their skin depth, calculated at the resonant frequency of the $\{m, n\}$ mode, $k_{0}$ the wavenumber, and $\eta_{0}$ the intrinsic impedance of vacuum, and the parameter $I_{\text {int }}$ directly proportional to the radiated power of the $\{m, n\}$ antenna mode is obtained from the far radiation field of the hybrid microstrip antenna. Here, as in [27], equivalent magnetic sources, positioned along the ungrounded patch walls, lead to the following expression $[9,28]$ :

$$
\vec{E}=\frac{k_{0}^{2} \eta_{0} I_{0} h}{a} \frac{e^{-i k_{0} r}}{r} g(\theta, \phi)[\widehat{\theta} \cos \phi-\widehat{\phi} \sin \phi \cos \theta],
$$

where

$$
\begin{aligned}
g(\theta, \phi)= & \sum_{m} \sum_{n} \frac{m \xi_{n}}{k_{\mathrm{ef}_{m n}}^{2}-k_{m n}^{2}}\left\{\frac{\cos (m \pi) e^{i k_{0} b \sin \theta \sin \phi}}{\left(k_{0} b \sin \theta \sin \phi\right)^{2}-(m \pi)^{2}}\right\} \\
& \cdot\left\{\cos (n \pi) e^{i k_{0} a \cos \theta}-1\right\} \\
& \times \sin \left(\frac{m \pi y_{c}}{b}\right) \cos \left(\frac{n \pi z_{c}}{a}\right) \sin \mathrm{c}\left(\frac{m \pi \ell_{p}}{2 b}\right) .
\end{aligned}
$$

Thus, the input impedance of the hybrid microstrip antenna is calculated from

$$
\begin{aligned}
Z_{\text {in }}= & \frac{i 2 h \omega \mu_{0}}{a b} \sum_{m} \sum_{n} \frac{\xi_{n}}{\left(k_{m n}^{2}-k_{\mathrm{ef}_{m n}}^{2}\right)} \\
& \times \sin ^{2}\left(\frac{m \pi y_{c}}{b}\right) \cos ^{2}\left(\frac{n \pi z_{c}}{a}\right) \sin c^{2}\left(\frac{m \pi \ell_{p}}{2 b}\right) .
\end{aligned}
$$

TABLE 1: Dimensions of the equivalent resonant cavities.

\begin{tabular}{lccc}
\hline Dimension & $\mathrm{HB}_{1}$ & $\mathrm{HB}_{2}$ & $\mathrm{HB}_{3}$ \\
\hline$a(\mathrm{~mm})$ & 40.00 & 54.19 & 133.30 \\
$b(\mathrm{~mm})$ & 133.30 & 54.19 & 40.00 \\
\hline
\end{tabular}

\section{Antenna Analysis}

In this section, the electromagnetic behavior of the hybrid microstrip antenna is analyzed with the purpose of establishing an effective predesigning procedure. As mentioned in $[16,28], \mathrm{TM}_{10}^{x}$ is the first resonant mode. Since its electric field does not vary along the $z$-axis, the fringing fields are in phase opposition, thus producing a null in the broadside direction of the antenna radiation pattern (perpendicularly to the $y z$ plane of Figure 1). In addition, its input impedance does not vary with $z_{\mathcal{c}}$, what makes impedance matching difficult. Given these undesirable characteristics, this first resonant mode is not adequate for the usual operation of microstrip antennas. On the other hand, the $\mathrm{TM}_{11}^{x}$ mode presents a cosinusoidal distribution along the $z$-axis over the length $a$ of the patch, thus permitting matching the antenna to the coaxial probe feeder. Since its fringing fields are in phase, the radiation pattern maximum occurs in the broadside direction. These characteristics make $\mathrm{TM}_{11}^{x}$ the mode of operation to hybrid microstrip antenna.

Since the resonant frequency of the $\mathrm{TM}_{11}^{x}$ mode is a function of both physical dimensions of the patch, antennas with different values of $a$ and $b$ can be designed for operation on a given frequency. Design criteria are therefore required for determining the patch dimensions $a$ and $b$ and the position $\left(y_{c}, z_{c}\right)$ of the coaxial probe feeder, to guarantee the proper operation of the antenna. For this purpose, three different hybrid radiators $\left(\mathrm{HB}_{1}, \mathrm{HB}_{2}\right.$, and $\left.\mathrm{HB}_{3}\right)$, designed to operate at $2.45 \mathrm{GHz}$, the central frequency of the ISM (industrial, scientific, and medical $2.4-2.5 \mathrm{GHz}$ ) band, are compared. The dimensions of their respective equivalent resonant cavities are shown in Table 1 , noting that $\mathrm{HB}_{1}$ has a rectangular patch, with $b>a ; \mathrm{HB}_{2}$ patch is square, with $b=a$; and $\mathrm{HB}_{3}$ has also a rectangular patch, but now with $b<a$. The substrate used for all three radiators is $1.524 \mathrm{~mm}$ thick Arlon CuClad 250GX $\left(\varepsilon_{r}=2.55 \pm 0.04\right.$ and $\left.\tan \theta=0.0022\right)$ microwave laminate.

Initially, the resonant frequencies of the modes that are the closest to $\mathrm{TM}_{11}^{x}$ are calculated from (4) and shown in Table 2. Thus, in the case of the $\mathrm{HB}_{1}$ antenna, modes $\{2,0\}$ and $\{2,1\}$ are the closest to $\mathrm{TM}_{11}^{x}$. For $\mathrm{HB}_{2}$, modes $\{1,0\}$ and $\{2,0\}$ are closest to $\mathrm{TM}_{11}^{x}$, whereas, in the $\mathrm{HB}_{3}$ case, modes $\{1,0\}$ and $\{1,2\}$ are the closest.

Also from Table 2, the frequency offset $\Delta f$ between the mode $\mathrm{TM}_{11}^{x}$ and its closest one is promptly determined. It is, for the $\mathrm{HB}_{1}$ antenna, $\Delta f_{1}=286.8 \mathrm{MHz}$; for $\mathrm{HB}_{2}, \Delta f_{2}=717.5 \mathrm{MHz}$; and for $\mathrm{HB}_{3}, \Delta f_{3}=103.4 \mathrm{MHz}$. The frequency bandwidth of conventional microstrip antennas operating in the fundamental mode is known to be roughly $1 \%$ [6-8] or approximately $25 \mathrm{MHz}$ in the ISM band. Hence, in practical terms, the proximity of modes $\mathrm{TM}_{10}^{x}, \mathrm{TM}_{20}^{x}$, $\mathrm{TM}_{21}^{x}$, and $\mathrm{TM}_{12}^{x}$ to the $\mathrm{TM}_{11}^{x}$ one will not significantly affect 
TABle 2: Resonant modes closest to $\mathrm{TM}_{11}^{x}$ (calculated in Mathematica [29]).

\begin{tabular}{lccc}
\hline Frequency $(\mathrm{GHz})$ & $\mathrm{HB}_{1}(b>a)$ & $\mathrm{HB}_{2}(b=a)$ & $\mathrm{HB}_{3}(b<a)$ \\
\hline$f_{10}$ & 0.7042 & 1.7322 & 2.3467 \\
$f_{11}$ & 2.4501 & 2.4497 & 2.4501 \\
$f_{20}$ & 1.4084 & 3.4644 & 4.6934 \\
$f_{12}$ & 4.7460 & 3.8734 & 2.7369 \\
$f_{21}$ & 2.7369 & 3.8734 & 4.7460 \\
\hline
\end{tabular}

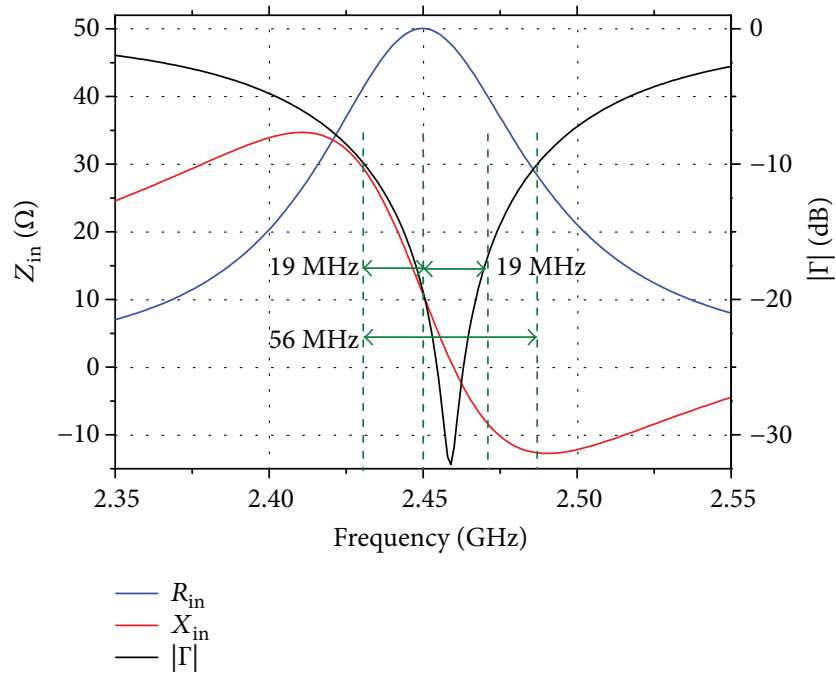

Figure 3: $\mathrm{HB}_{1}$ input impedance and reflection coefficient module.

the operating frequency bandwidth of electrically thin hybrid antennas. Thus, from the perspective of modal interference, any one of the three designed antennas could be used. Nonetheless, a simple way to suppress modes $\mathrm{TM}_{20}^{x}$ and $\mathrm{TM}_{21}^{x}$ consists of placing the feeder at $y_{c}=b / 2$, where their electric field is minimal $[9,16,28]$. In such case, only modes $\{1,0\}$ and $\{1,2\}$ need to be controlled in the antenna design.

Consequently, the input impedance at the operation mode $\mathrm{TM}_{11}^{x}$ can be rewritten from (12) as

$$
Z_{\text {in }}=\frac{i \omega \alpha_{11}}{k_{11}^{2}-k_{\mathrm{ef}_{11}}^{2}}+i \omega \sum_{m, m \neq 1} \sum_{n, n \neq 1} \frac{a_{m n}}{k_{m n}^{2}-k^{2}}
$$

where

$$
\alpha_{m n}=\frac{2 \mu_{0} h \xi_{n}}{a b} \sin ^{2}\left(\frac{m \pi y_{c}}{b}\right) \cos ^{2}\left(\frac{n \pi z_{c}}{a}\right) \operatorname{sinc}^{2}\left(\frac{m \pi \ell_{p}}{2 b}\right) .
$$

With that, the next step consisted of determining the value of $z_{c}$ such that the input impedance matches the $50 \Omega$ characteristic impedance of the feeding probe SMA connector (Figure 1). Plots of $Z_{\text {in }}$ and the absolute value of the reflection coefficient, also obtained in Mathematica from (13) and (14) (for $\ell_{p}=1.3 \mathrm{~mm}$ ), are shown in Figures 3-5 for the three antennas.

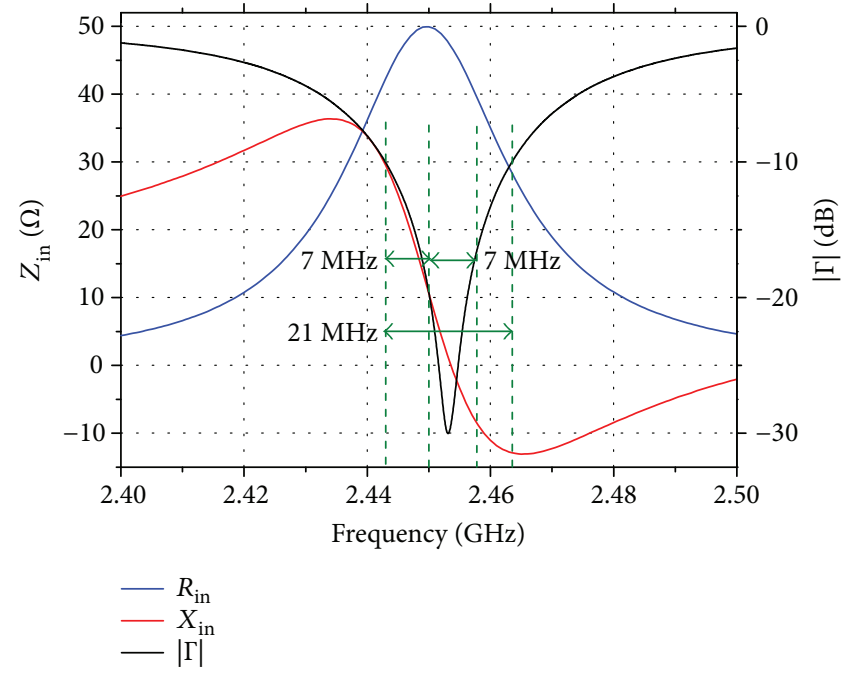

FIgURE 4: $\mathrm{HB}_{2}$ input impedance and reflection coefficient module.

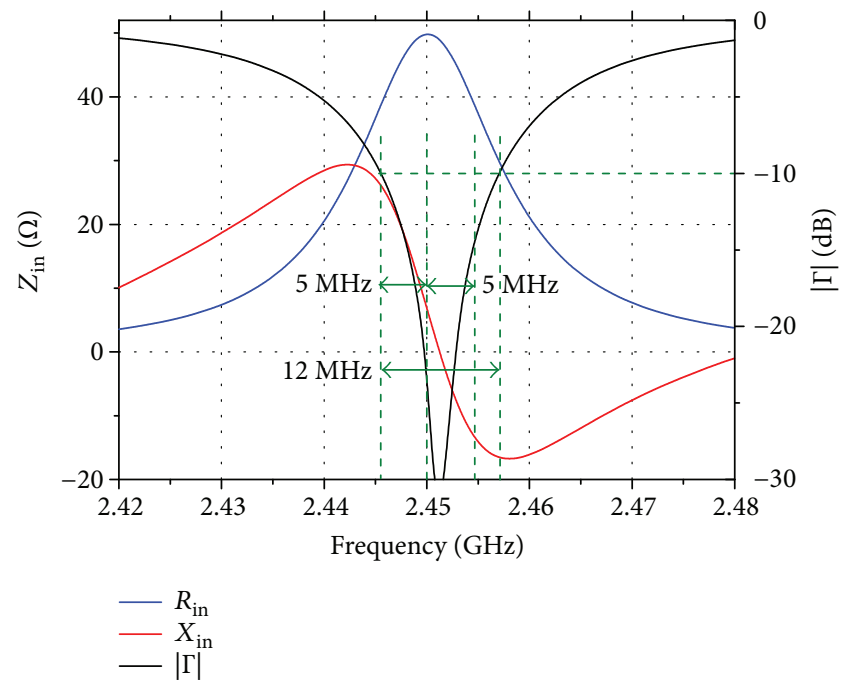

Figure 5: $\mathrm{HB}_{3}$ input impedance and reflection coefficient module.

TABLE 3: Electrical characteristics of the antennas under analysis.

\begin{tabular}{lccc}
\hline & $\mathrm{HB}_{1}(b>a)$ & $\mathrm{HB}_{2}(b=a)$ & $\mathrm{HB}_{3}(b<a)$ \\
\hline$Z_{\text {in }}(\Omega)(2.45 \mathrm{GHz})$ & $50.05+i 10.72$ & $49.94+i 10.61$ & $50.04+i 6.89$ \\
$z_{c}(\mathrm{~mm})$ & 9.72 & 21.33 & 52.66 \\
$\mathrm{BW}(\%)$ & 2.29 & 0.84 & 0.47 \\
$Q$ & 29.19 & 79.67 & 141.35 \\
\hline
\end{tabular}

In addition, the resulting frequency bandwidth (BW) and quality factor $(Q)$ are presented in Table 3, both calculated at $2.45 \mathrm{GHz}$.

As shown in Table 3 and in Figures 3-5, the three hybrid antennas exhibit inductive input impedances at the design frequency $(2.45 \mathrm{GHz})$, as expected from a coaxial probe feed. It is also noticed that the bandwidth for the $\mathrm{HB}_{1}$ antenna is larger than that for the $\mathrm{HB}_{2}$ antenna and that for the $\mathrm{HB}_{2}$ antenna is larger than that for the $\mathrm{HB}_{3}$ one. This is directly related to side $b$ being longer than side $a$-for the larger the 
$b$ dimension is, the smaller the input impedance will be at the antenna edges, that is, at $z_{c}=0$ or at $z_{c}=a$, resulting in a smoother dependence of $Z_{\text {in }}$ with $z_{c}$. Besides compromising the antenna impedance matching at the design frequency, an inductive $Z_{\text {in }}$, makes for an asymmetrical bandwidth around the center frequency, thus reducing its symmetrical operating bandwidth (i.e., $|\Gamma|<-10 \mathrm{~dB}$ for the same frequency spacing both left and right of the design frequency). As shown in Figures 3-5, the bandwidth comes from 56 down to $38 \mathrm{MHz}$, for $\mathrm{HB}_{1}$; from 21 down to $14 \mathrm{MHz}$, for $\mathrm{HB}_{2}$; and from 12 to $10 \mathrm{MHz}$, for $\mathrm{HB}_{3}$. Besides, the larger the antenna bandwidth, the lower its $Q$ factor, as expected from the product $B W \times Q=0.6667$. Thus, from the point of view of frequency bandwidth, the design of hybrid antennas should achieve $a<b$. The effect of this criterion on the radiation pattern of hybrid antennas is analyzed next.

Since now only modes $\{1,0\}$ and $\{1,2\}$ need to be controlled, the far electric field can be rewritten from (10) and $(11)$ as $[9,28]$

$$
\begin{aligned}
\vec{E}=A_{0} f(\theta, \phi) \sum_{n=0}^{2}\left\{\frac{\xi_{n}}{k_{\mathrm{ef}_{1 n}}^{2}-k_{1 n}^{2}} \cos \left(\frac{n \pi z_{c}}{a}\right)\right. \\
\left.\times\left[\cos (n \pi) e^{i k_{0} a \cos \theta}-1\right]\right\} \\
\cdot[\sin \phi \cos \theta \widehat{\phi}-\cos \phi \widehat{\theta}],
\end{aligned}
$$

where

$$
\begin{aligned}
A_{0} & =\frac{k_{0}^{2} \eta_{0} I_{0} h}{a} \frac{e^{-i k_{0} r}}{r} \sin \left(\frac{\pi y_{c}}{b}\right) \operatorname{sinc}\left(\frac{\pi \ell_{p}}{2 b}\right), \\
f(\theta, \phi) & =\frac{e^{i k_{0} b \sin \theta \sin \phi}+1}{\left(k_{0} b \sin \theta \sin \phi\right)^{2}-\pi^{2}} .
\end{aligned}
$$

Since the $z$-axis of the adopted rectangular coordinate system is normal to the magnetic currents at the ungrounded edges of the patch (Figure 1), the $E_{\theta}$ component in (15) defines the copolarization of the hybrid antenna, whereas the cross-polarization is given by $E_{\phi}$. Implementing (15) in Mathematica, radiation patterns for the $\mathrm{HB}_{1}, \mathrm{HB}_{2}$, and $\mathrm{HB}_{3}$ antennas were plotted at $2.45 \mathrm{GHz}$ as shown in Figures 6-8. It is noticed that the patterns are asymmetrical in the $E(x z)$ and $y z$ planes.

Analysis of Figure 1 indicates that the coaxial feeder location introduces an asymmetry in the antenna geometry, by making the field distribution asymmetrical within the equivalent resonant cavity, which what reflects in the radiated field. One also notices, however, that in the $H(x y)$ plane the antenna is perfectly symmetrical. The $3 \mathrm{D}$ radiation patterns in Figure 9 permit a clearer visualization.

Shown in Table 4 are the results from the Mathematica simulation of the directivity $(D)$ and radiation efficiency (RE) of the antennas under analysis. One notes that $\mathrm{HB}_{1}$ and $\mathrm{HB}_{2}$ are equally directive. Nonetheless, the total field structure in $\mathrm{HB}_{2}$ is more uniform, with better balanced $3 \mathrm{~dB}$ angles, circa $69^{\circ}$ in the $E(x z)$ plane, and $80.5^{\circ}$ in the $H(x y)$ plane, as opposed to the wide discrepancy between those

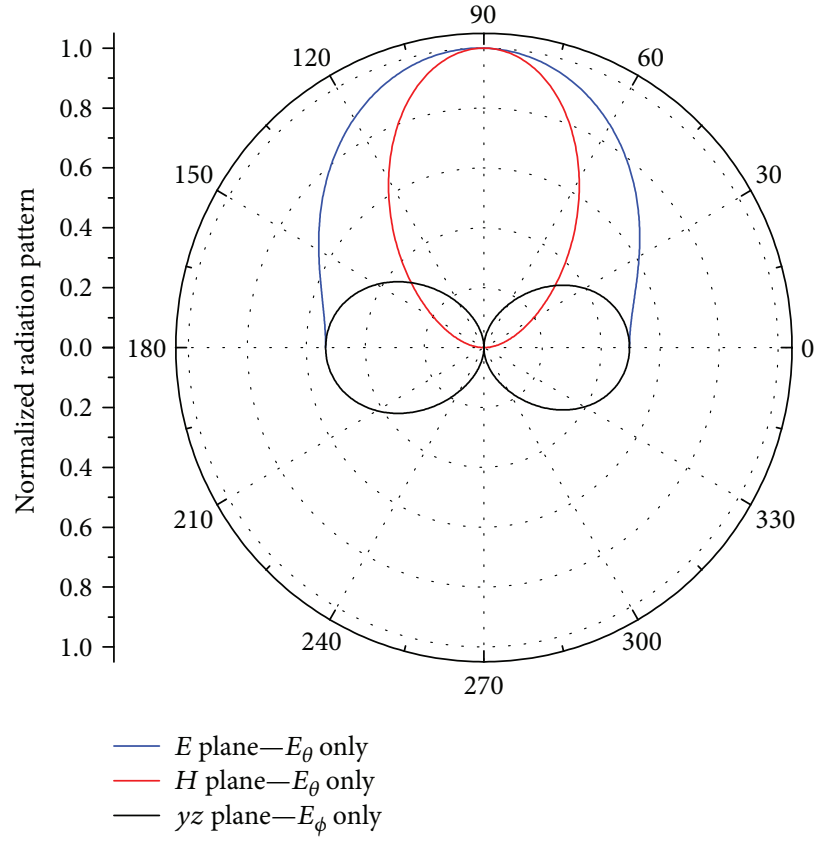

FIgURE 6: Normalized radiation pattern of the $\mathrm{HB}_{1}$ antenna.

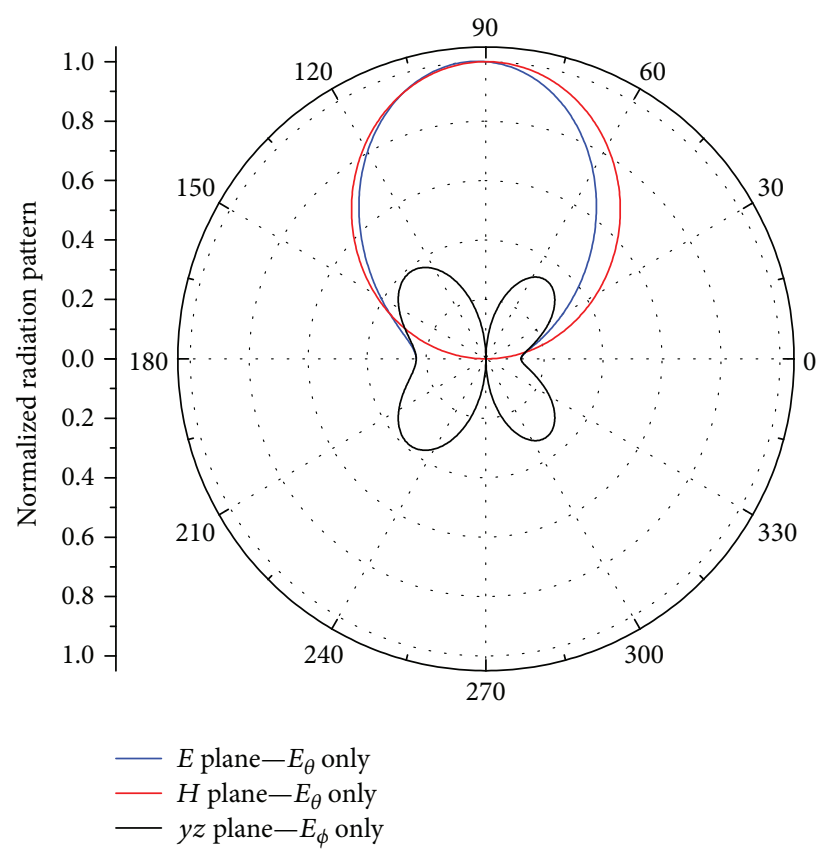

FIgURE 7: Normalized radiation pattern of the $\mathrm{HB}_{2}$ antenna.

angles for antenna $\mathrm{HB}_{1}$, that is, $99.88^{\circ}$ in the $E(x z)$ plane and $53.5^{\circ}$ in the $H(x y)$ plane. It is also noticed in Figure 9 that the radiation pattern of $\mathrm{HB}_{3}$ shows considerable secondary lobes, which what makes its directivity less than that of the $\mathrm{HB}_{1}$ and $\mathrm{HB}_{2}$ antennas.

Another relevant parameter is the copolarization directivity $D_{\text {cop }}$, promptly calculated in the adopted coordinate system. In this case, only the $E_{\theta}$ component is taken into account. The difference between $D_{\text {cop }}$ and the directivity $D$ is due to the intensity of the antenna cross-field (component $E_{\phi}$ ), which varies substantially from one antenna to another 


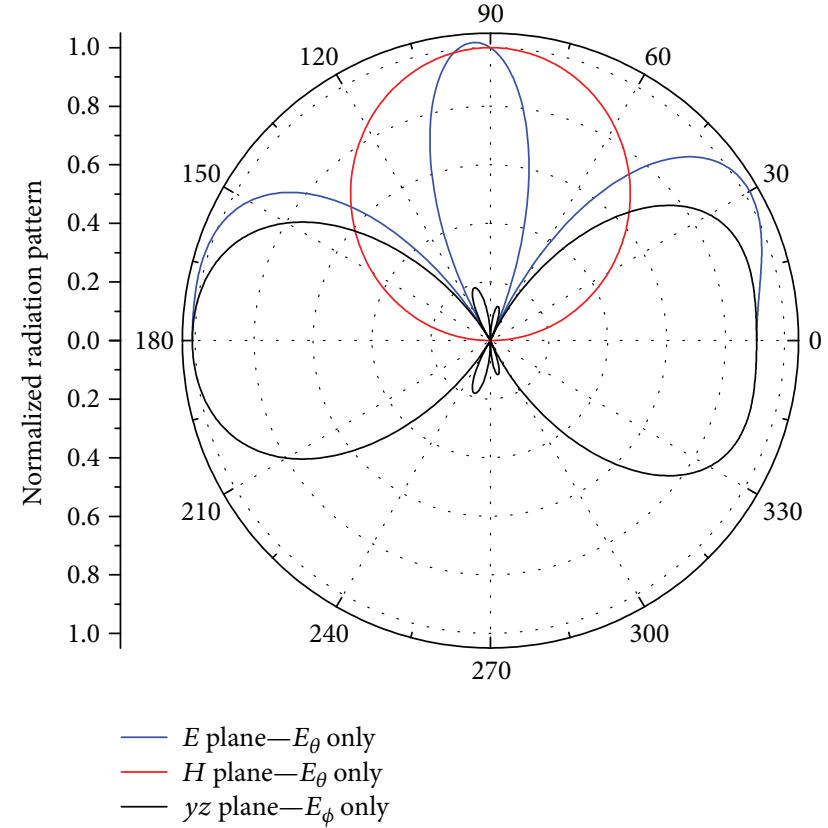

FIgURE 8: Normalized radiation pattern of the $\mathrm{HB}_{3}$ antenna.

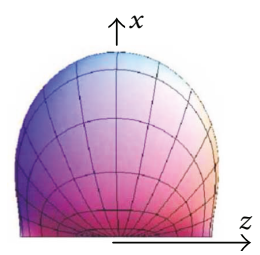

(A) Co-polarization

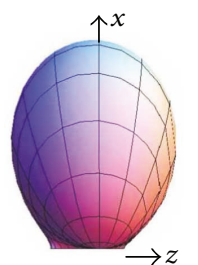

(A) Co-polarization

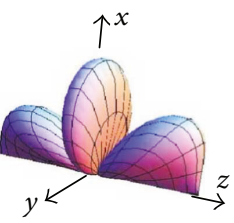

(A) Co-polarization

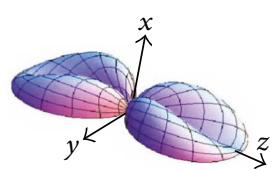

(B) Cross-polarization

(a) $\mathrm{HB}_{1}$ antenna

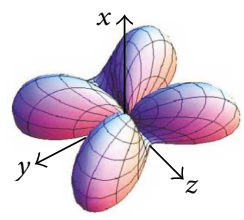

(B) Cross-polarization

(b) $\mathrm{HB}_{2}$ antenna

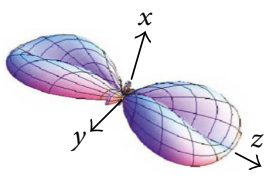

(B) Cross-polarization

(c) $\mathrm{HB}_{3}$ antenna

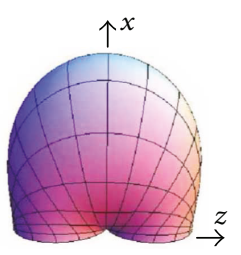

(C) Total field

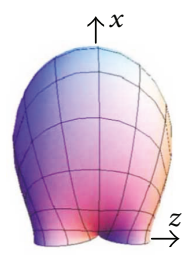

(C) Total field

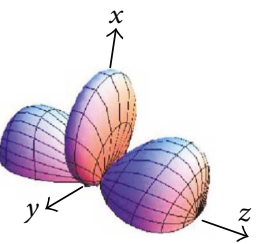

(C) Total field
Figure 9: $3 \mathrm{D}$ radiation patterns of $\mathrm{HB}_{1}, \mathrm{HB}_{2}$, and $\mathrm{HB}_{3}$ antennas.

(Figure 9(B)), although it is null on the $E$ and $H$ planes. This means a hybrid microstrip antenna does not exhibit crosspolarization on the main radiation planes $x z$ and $x y$, differently from the significant cross-polarization level on the $H$ plane of a conventional antenna [5]. Such is a relevant
TABLE 4: Directivity and radiation efficiency.

\begin{tabular}{lccc}
\hline & $\mathrm{HB}_{1}(b>a)$ & $\mathrm{HB}_{2}(b=a)$ & $\mathrm{HB}_{3}(b<a)$ \\
\hline$D(\mathrm{~dB})$ & 8.33 & 8.23 & 7.39 \\
$D_{\text {cop }}(\mathrm{dB})$ & 8.98 & 8.84 & 8.85 \\
$\mathrm{RE}(\%)$ & 90.4 & 74.1 & 50.9 \\
\hline
\end{tabular}

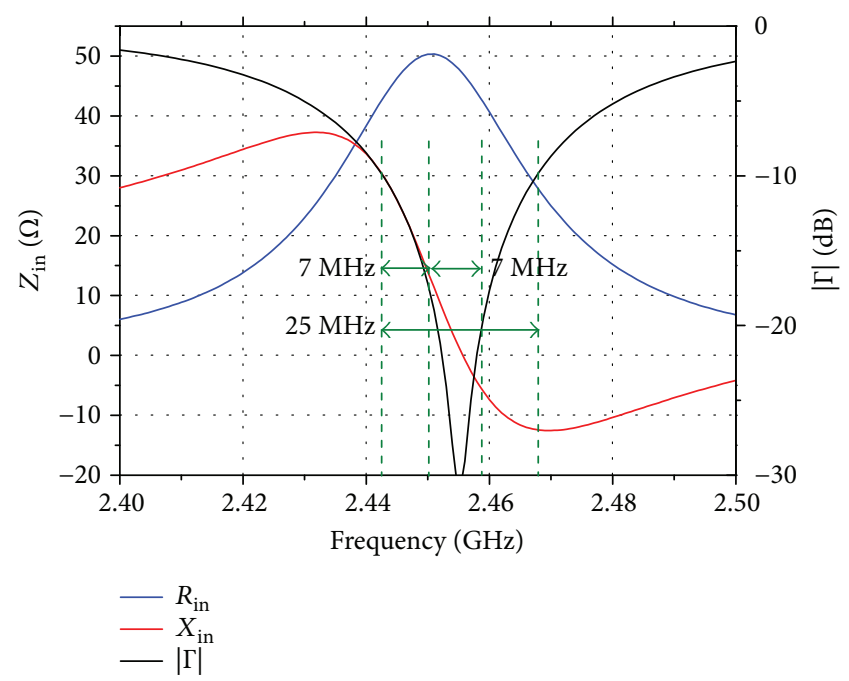

Figure 10: HB input impedance and reflection coefficient module.

property of hybrid antennas. Also shown in Table 4 are the results obtained for the radiation efficiency; that is, the $\mathrm{HB}_{1}$ antenna outweighs both, whereas $\mathrm{HB}_{3}$ is the worst.

From these considerations, if the goal is to provide an operation equivalent to the conventional antenna, the hybrid antenna design should go for a modified square patch, with $b \geq a$, for, in this case, the antenna directivity will be in the order of $8 \mathrm{~dB}$, its radiation efficiency close to $80 \%$, frequency bandwidth around $1 \%$, and $3 \mathrm{~dB}$ angles balanced in the $E$ and $H$ planes. The complete antenna design will be accomplished in the next section.

\section{Antenna Design}

Given the condition $b \geq a$, a hybrid antenna (HB) was designed for operation in the same frequency $(2.45 \mathrm{GHz})$ of the antennas that were analyzed in the previous section. For the substrate, the $1.524 \mathrm{~mm}$ thick Arlon CuClad 250GX $\left(\varepsilon_{r}=2.55\right.$ and $\left.\tan \theta=0.0022\right)$ was used again. Through Mathematica, the following dimensions were obtained: $a=$ $50.00 \mathrm{~mm}, b=59.59 \mathrm{~mm}, y_{c}=b / 2$, and $x_{c}=19.05 \mathrm{~mm}$. In this case, the resonant modes closest to $\mathrm{TM}_{11}^{x}$ are $\mathrm{TM}_{10}^{x}$ at $f_{10}=1.575 \mathrm{GHz}$ and $\mathrm{TM}_{20}^{x}$ at $f_{20}=3.150 \mathrm{GHz}$. For a frequency bandwidth in the order of $1 \%$, the antenna design is good enough in this respect.

Input impedance and the reflection coefficient module, for $\ell_{p}=1.3 \mathrm{~mm}$, are plotted in Figure 10. As expected, the $\mathrm{HB}$ input impedance turns out to be inductive at the design frequency $\left(Z_{\text {in }}=50.30+i 13.99 \Omega\right)$, so the best matching occurs above $2.45 \mathrm{GHz}$. Consequently, the symmetrical 


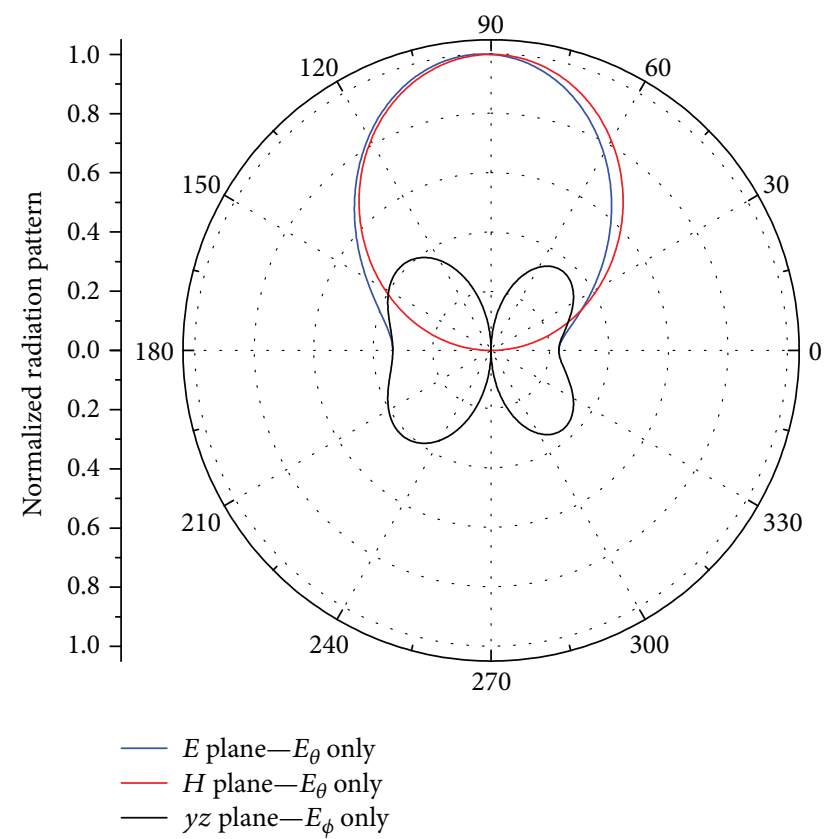

FIGURE 11: Normalized radiation pattern of the HB antenna.

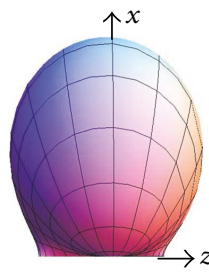

(a) Copolarization

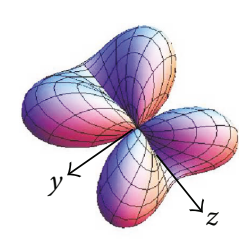

(b) Cross-polarization

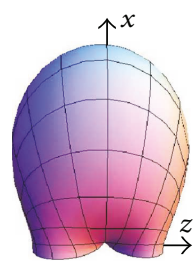

(c) Total field
Figure 12: 3D pattern for the HB antenna.

passband of the antenna, in relation to the central operating frequency, goes down from $25 \mathrm{MHz}$ to $14 \mathrm{MHz}$, as shown in Figure 10.

Results for the radiation patterns in the principal planes, at $2.45 \mathrm{GHz}$, are shown in Figure 11. As expected, the antenna is asymmetrical in the $E$ plane. For a better visualization of this effect, 3D patterns, at the same frequency, are presented in Figure 12.

As intended, the design process produced a uniform radiation pattern, with balanced $3 \mathrm{~dB}$ angles: circa $75.63^{\circ}$ in the $E$ plane and $78.50^{\circ}$ in the $H$ plane. In addition, the antenna shows $7.9 \mathrm{~dB}$ directivity, $78.6 \%$ radiation efficiency, and $1.02 \%$ relative frequency bandwidth, all calculated at $2.45 \mathrm{GHz}$.

As noticed from Figure 12(b), no cross field exists in the broadside direction or along the $E$ and $H$ planes. Rather, it is more intense close to the antenna ground plane and on the planes that bisect the quadrants formed by planes $(x y)$ and $(x z)$. Consequently, its most significant effect consists of "beefing up" the total field pattern in the neighborhood of the ground plane, thus lowering the antenna directivity (to circa $7.9 \mathrm{~dB}$ ) relative to the copolarization $\left(D_{\text {cop }}\right)$, calculated as $8.6 \mathrm{~dB}$, in this case.
The asymmetrical radiation pattern in the $E$ plane is now analyzed. Since the $E$ plane of a hybrid antenna, as shown in Figure 1, coincides with the $x z$ plane of the adopted coordinate system, its far electric field is given by making $\phi=0^{\circ}$ in (15). Thus, the following expression for the normalized $E_{\theta}$ component results, given $E_{\phi}$ is zero on this plane [28],

$$
\begin{aligned}
e_{\theta}= & \left\{\left[\frac{1}{k_{\mathrm{ef}_{10}}^{2}-k_{10}^{2}}+\frac{2 \cos \left(2 \pi z_{c} / a\right)}{k_{\mathrm{ef}_{12}}^{2}-k_{12}^{2}}\right]\left(e^{i k_{0} a \cos \theta}-1\right)\right. \\
& \left.-\frac{2 \cos \left(\pi z_{c} / a\right)}{k_{\mathrm{ef}_{11}}^{2}-k_{11}^{2}}\left(e^{i k_{0} a \cos \theta}+1\right)\right\},
\end{aligned}
$$

which can be rewritten as

$$
\begin{aligned}
e_{\theta}=2\{ & i\left(e_{10}+e_{12}\right) \sin \left[\frac{\left(k_{0} a \cos \theta\right)}{2}\right] \\
& \left.-e_{11} \cos \left[\frac{\left(k_{0} a \cos \theta\right)}{2}\right]\right\} e^{i\left(k_{0} a \cos \theta\right) / 2},
\end{aligned}
$$

where

$$
\begin{aligned}
& e_{11}=\frac{2 \cos \left(\pi z_{c} / a\right)}{k_{\mathrm{ef}_{11}}^{2}-k_{11}^{2}}, \\
& e_{10}=\frac{1}{k_{\mathrm{ef}_{10}}^{2}-k_{10}^{2}}, \\
& e_{12}=\frac{2 \cos \left(2 \pi z_{c} / a\right)}{k_{\mathrm{ef}_{12}}^{2}-k_{12}^{2}} .
\end{aligned}
$$

From (13), mode $\{1,0\}$ and mode $\{1,2\}$ characteristics are seen to be opposite from the primary mode; that is, at the operating frequency, $e_{11}$ is imaginary, whereas $e_{10}$ and $e_{12}$ are real. In the case of the $\mathrm{HB}$ antenna at the operating frequency, they are $e_{11}=i 0.00696845, e_{10}=i 0.000253281$, and $e_{12}=i 0.000123797$. Thus, in the first quadrant, where $\theta$ ranges from 0 to 90 degrees, the terms $\sin \left[\left(k_{0} a \cos \theta / 2\right)\right]$ and $\cos \left[\left(k_{0} a \cos \theta / 2\right)\right]$ are positive, so their subtraction lowers the amplitude of $e_{\theta}$ relative to the primary mode amplitude $e_{11} \cos \left[\left(k_{0} a \cos \theta\right) / 2\right]$. In the second quadrant, on the other hand, where $\theta$ ranges from 90 to 180 degrees, a negative $\cos \theta$ changes the sign of the term $\sin \left[\left(k_{0} a \cos \theta\right) / 2\right]$; consequently, the amplitude of $e_{\theta}$ is now larger than the primary mode one $e_{11} \cos \left[\left(k_{0} a \cos \theta\right) / 2\right]$, resulting in an asymmetrical radiation pattern in the $E$ plane. In addition, analysis of (19), (20), and (21) shows that $e_{10}$ is not dependent on $z_{\mathrm{c}}$, but $e_{11}$ and $e_{12}$ are. This fact is directly related to the resonant mode field distribution along the plane $y_{c}=b / 2$. In fact,

$$
E_{x}\left(\frac{b}{2}, z\right)_{m n}=E_{m n} \cos \left(\frac{n \pi z_{c}}{a}\right) .
$$

Therefore, the excitation of mode $\{1,0\}$ does not depend on the feeder position $z_{c}$ (along the $y_{c}=b / 2$ plane), but $z_{\mathrm{c}}$ substantially affects the level of $\{1,1\}$ and $\{1,2\}$ modes, thus becoming one of the causes of the $E$ plane radiation pattern asymmetry of hybrid microstrip antennas. Normalized $E$ plane radiation patterns for the $\mathrm{HB}$ antenna are shown in 


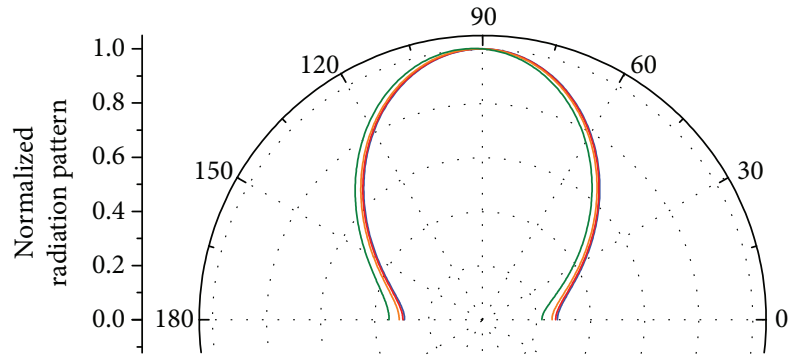

FIGURE 13: Normalized $E$ plane radiation pattern of the HB antenna: $z_{c}=5 \mathrm{~mm}$-blue curve; $z_{c}=10 \mathrm{~mm}$-red curve; $z_{c}=15 \mathrm{~mm}$-orange curve; and $z_{c}=20 \mathrm{~mm}$ - green curve.

TABLe 5: HB antenna dimensions $\left(W_{z}=140 \mathrm{~mm} ; W_{y}=140 \mathrm{~mm}\right)$.

\begin{tabular}{lcc}
\hline Dimension & Hammerstad & HFSS \\
\hline$a_{a}(\mathrm{~mm})$ & 48.45 & 48.28 \\
$b_{a}(\mathrm{~mm})$ & 59.59 & 59.59 \\
$y_{a}(\mathrm{~mm})$ & 29.80 & 29.80 \\
$z_{a}(\mathrm{~mm})$ & 18.27 & 18.18 \\
\hline
\end{tabular}

Figure 13 for different feeder positions at $2.45 \mathrm{GHz}$. They clearly show that pattern asymmetry increases with $z_{c}$. That is, the lower the antenna input impedance is, the more asymmetrical the $E$ plane pattern is. This fact is noticeable from (18), since the larger $z_{c}$ is, the smaller the contribution from the $e_{11}$ term, whereas the larger that from $e_{12}$ will be for a fixed $e_{10}$.

\section{HFSS Comparison}

In order to validate the analysis and design procedures set forth, simulations were run in HFSS. The initial predesigned dimensions of the $\mathrm{HB}$ antenna, adjusted according to Hammerstad [30], are presented in Table 5. For the HFSS simulations, the antenna was centered on a ground plane of dimensions $W_{z} \times W_{y}$, where the subscripts indicate the ground plane sides parallel to the coordinate axes $z$ and $y$. It is noticed from Table 5 that the predesigned dimensions are very close to the ones simulated via HFSS, besides being obtained in a significantly reduced processing time.

Results for the antenna input impedance are shown in Figure 14, whereas the comparisons between the predesigned results and those obtained via HFSS are presented in Table 6.

The good agreement between these results confirms the effectiveness of the equivalent resonant cavity for predesigning hybrid antennas. Nevertheless, for $\ell_{p}=1.3 \mathrm{~mm}$, the predesigned impedance turns out to be more inductive than the HFSS simulation result. One way to reduce the input inductive reactance consists of increasing the effective width of the current strip feeder. The effect of different values of $\ell_{p}$ is also plotted in Figure 14, showing the optimal $\ell_{p}$ value is somewhere between 1.6 and $2.8 \mathrm{~mm}$. Curves for $Z_{\text {in }}$ calculated for $\ell_{p}=2.3 \mathrm{~mm}$ are presented in Figure 15 .

Last, radiation patterns in the $E$ ( $x z$ plane-in blue) and $H$ ( $x y$ plane-in red) planes are shown in Figure 16. The

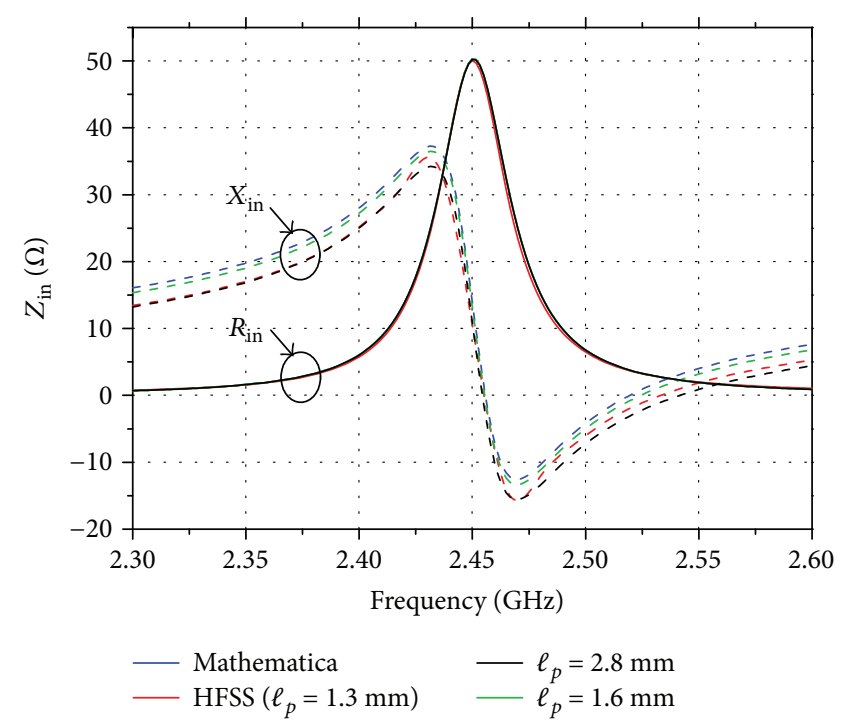

FIGURE 14: Input impedance of the HB antenna.

TABle 6: Input impedance at $2.45 \mathrm{GHz}$.

\begin{tabular}{lc}
\hline & HB \\
\hline$Z_{\text {in }}(\Omega)$ - equivalent cavity & $50.30+i 13.99$ \\
$Z_{\text {in }}(\Omega)$-HFSS & $50.02+i 10.36$ \\
\hline
\end{tabular}

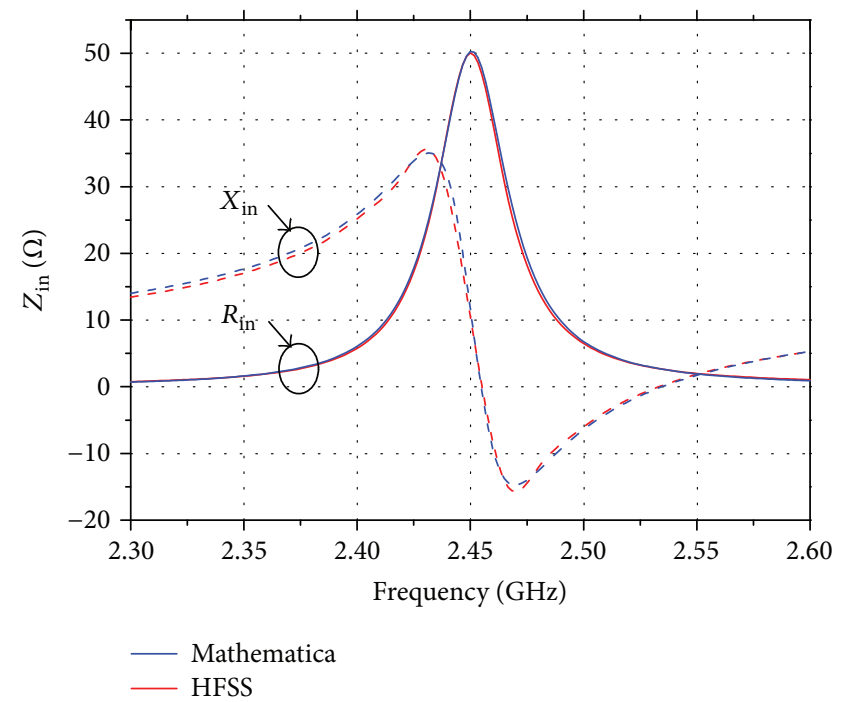

FIGURE 15: Input impedance of the HB antenna: $\ell_{p}=2.3 \mathrm{~mm}$.

HFSS patterns were simulated for an infinite ground plane. The excellent agreement confirms once again the effectiveness of the equivalent resonant cavity model for predesigning hybrid antennas.

It is worth mentioning that the $\mathrm{HB}$ antenna, although electrically thin at $2.45 \mathrm{GHz}$, shows an inductive input impedance, $Z_{\text {in }}=50.26+i 11.78 \Omega\left(\ell_{p}=2.3 \mathrm{~mm}\right)$, which shifted up the best matching frequency, causing a significant reduction of its symmetrical operating bandwidth. In the 


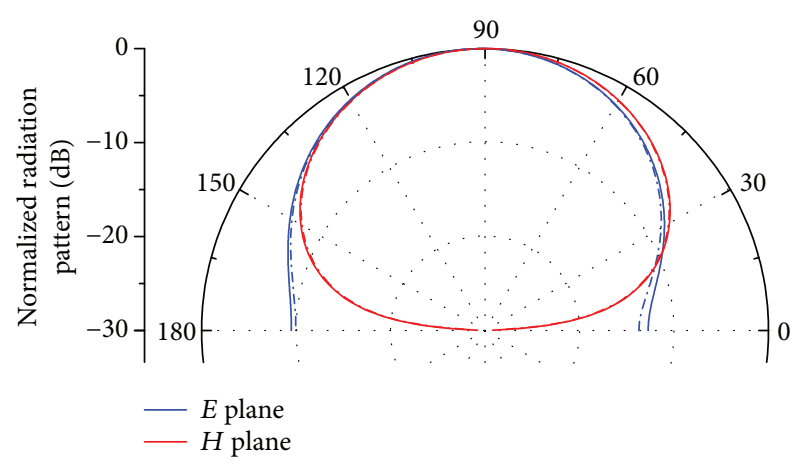

FIGURE 16: Normalized radiation pattern in the $E$ and $H$ planes of the HB antenna: solid line-Mathematica; dotted line-HFSS.

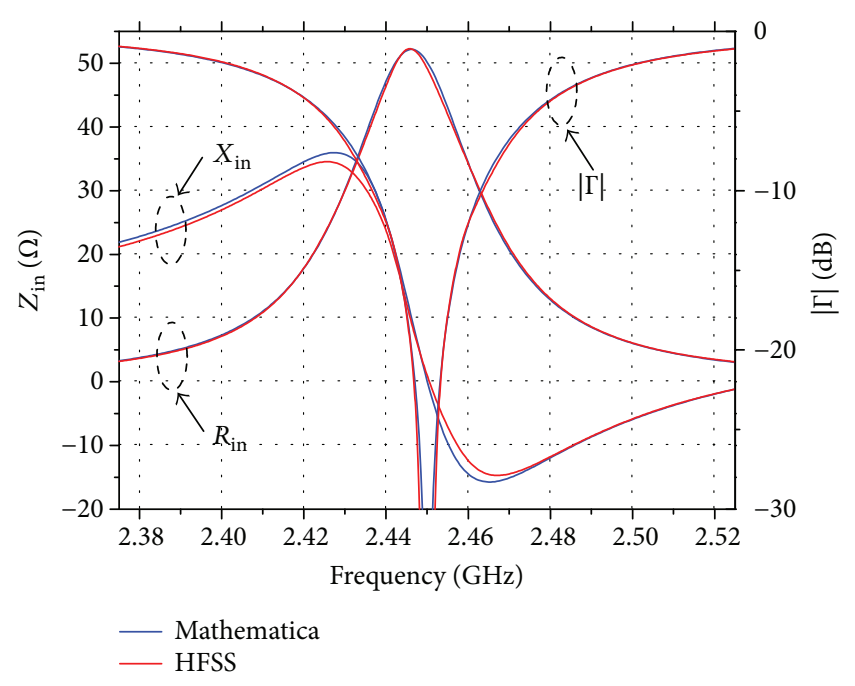

Figure 17: Input impedance and reflection coefficient module.

TABle 7: Antenna dimensions for null reactance design. $\left(W_{z}=\right.$ $140 \mathrm{~mm} ; W_{y}=140 \mathrm{~mm}$ ).

\begin{tabular}{lcc}
\hline Dimension & Hammerstad & HFSS \\
\hline$a_{a}(\mathrm{~mm})$ & 48.51 & 48.31 \\
$b_{a}(\mathrm{~mm})$ & 59.75 & 59.75 \\
$y_{a}(\mathrm{~mm})$ & 29.88 & 29.88 \\
$z_{a}(\mathrm{~mm})$ & 18.17 & 18.05 \\
\hline
\end{tabular}

following section, the HB antenna will be optimized at the operating frequency in terms of impedance matching to its SMA connector feeder.

\section{Project Optimization for Null Reactance}

A very effective way to match the antenna to the $50 \Omega$ characteristic impedance of its SMA connector feeder, without any external resource, consists of adjusting the antenna design for the null reactance condition [31]. With that, the following dimensions were obtained for the equivalent cavity: $a=50.06 \mathrm{~mm}, b=59.75 \mathrm{~mm}$, and $y_{c}=b / 2$ e $z_{c}=18.95 \mathrm{~mm}$. The resulting input impedance and reflection coefficient module are shown in Figure 17.

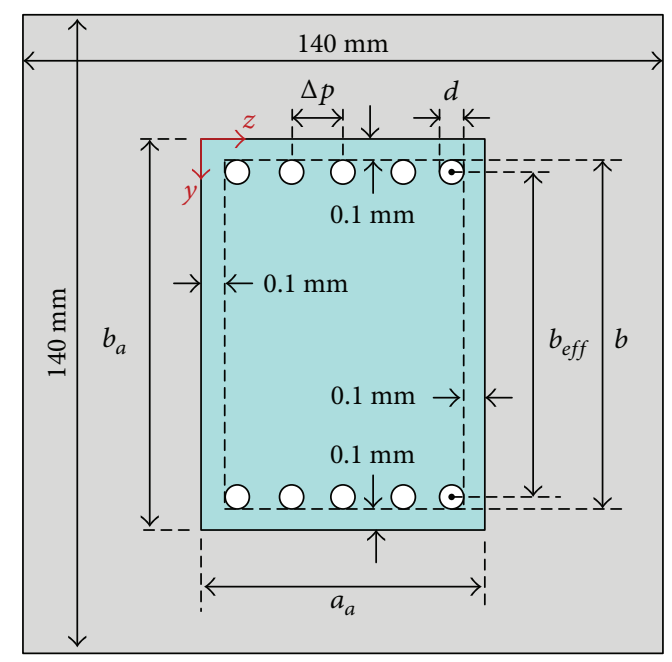

FIGURE 18: SIW antenna geometry: top view.

After its redesign for null reactance, the antenna is much better matched to its feeding SMA connector, with $Z_{\text {in }}=50.19-i 0.15 \Omega$ at $2.45 \mathrm{GHz}$. It is also noticed the $26 \mathrm{MHz}$ (circa 1.06\%) bandwidth is now symmetrical around the design frequency. Other electrical characteristics remain very close to the previous $\mathrm{HB}$ design.

The antenna dimensions after adjusting per Hammerstad are shown in Table 7, whereas the results for the input impedance and the reflection coefficient module are superimposed in Figure 17. Once again, the excellent agreement between predesigned and HFSS results confirms the effectiveness of the equivalent resonant cavity model for predesigning hybrid antennas.

\section{SIW Prototype}

To validate further the proposed design approach, a prototype antenna was built and tested, as described in this section. Given the implementation of vertical electric walls through the substrate in microstrip structures is not an easy task, an effective alternative approach is the use of SIW technology. In the present case, the vertical metallic walls are implemented with a sequence of cylindrical pins, as illustrated in Figure 18, in which $\Delta p$ is their center-to-center spacing. The SIW antenna dimensions were determined from the values presented in Table 7 .

First, the $b$ dimension was determined in order to make $b_{\text {eff }}$ equal to $59.75 \mathrm{~mm}$, based on the following relationship,

$$
b_{\text {eff }}=b-\frac{d^{2}}{0.95 \Delta p}
$$

set up in [32] for the propagation of the $\mathrm{TM}_{01}$ mode in SIW guiding structures, where $d$ denotes the pin diameter. After further optimization in HFSS, the following dimensions were obtained: $a_{a}=47.63 \mathrm{~mm}, b_{a}=60.52 \mathrm{~mm}, y_{a}=29.875 \mathrm{~mm}$, and $z_{a}=17.64 \mathrm{~mm}$, with $d=0.508 \mathrm{~mm}$ and $\Delta p=4.266 \mathrm{~mm}$. Based on those, radiation patterns in the $E$ ( $x z$ plane-in blue) and $H$ ( $x y$ plane-in red) planes, simulated in HFSS, are presented in Figure 19. 


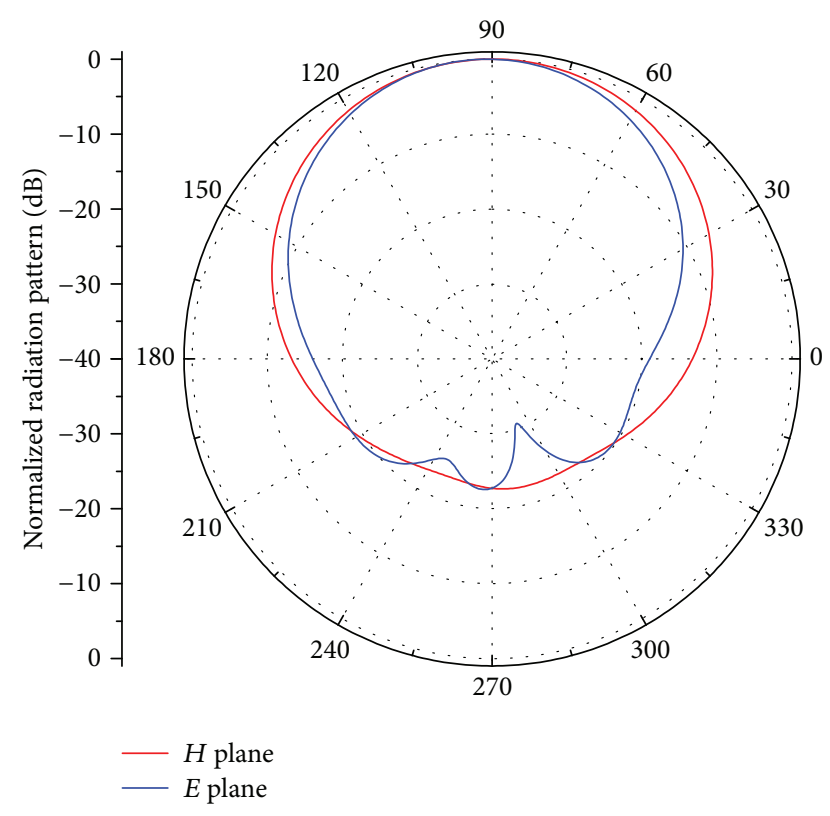

FIGURE 19: Normalized radiation pattern of the SIW antenna.

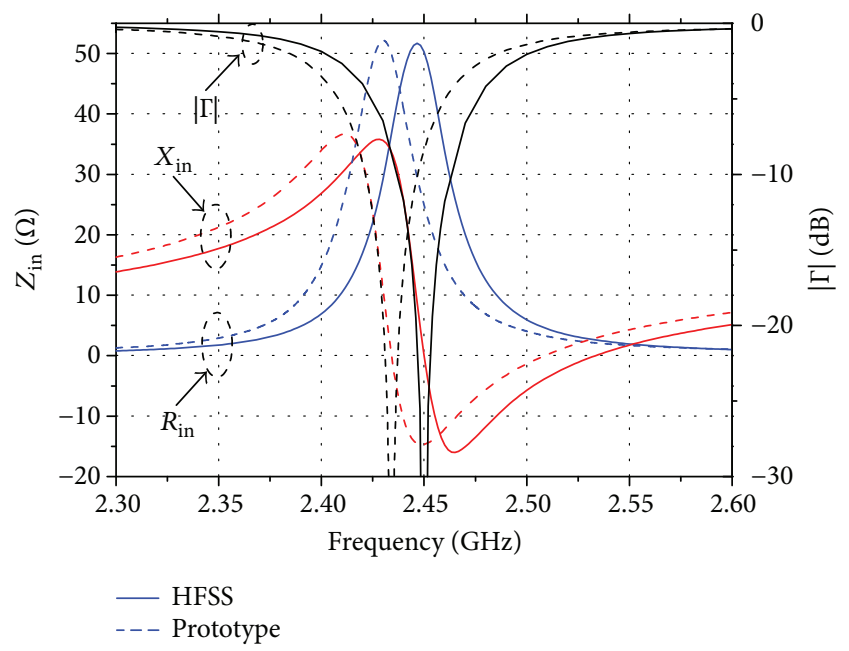

FIGURE 20: Input impedance and reflection coefficient module of the SIW antenna, designed under the null reactance condition.

Results for the input impedance and the reflection coefficient module are presented in Figure 20. Other electrical characteristics of the SIW antenna are the following: 49.99 $-i 0.79 \Omega$ input impedance, $80.5 \%$ radiation efficiency, $8.02 \mathrm{~dB}$ directivity, and balanced $3 \mathrm{~dB}$ angles in the $E$ and $H$ planes: circa $76^{\circ}$ on the $E$ plane and $78^{\circ}$ on the $H$ plane, consistently with the predesigned values.

With those dimensions established in HFSS, a prototype antenna was manufactured, as shown in Figure 21, and tested. Experimental results for the input impedance and reflection coefficient module are shown in Figure 20, overlaid to the simulation results. As noted, the prototype resonant frequency was $16 \mathrm{MHz}$ below requirement $(2.45 \mathrm{GHz})$. Confidence in the simulation results and in the manufacturing process led us to believe this effect could be caused by a printed circuit board (PCB) permittivity shift from its

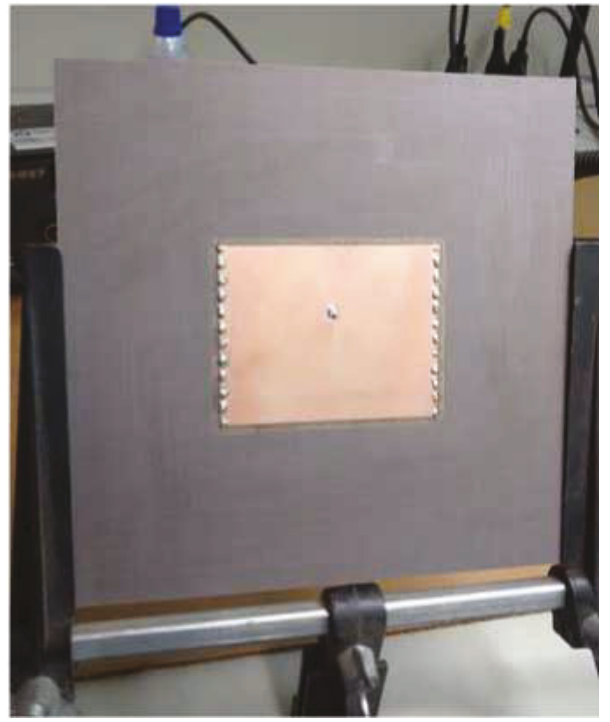

FIGURE 21: SIW antenna prototype.

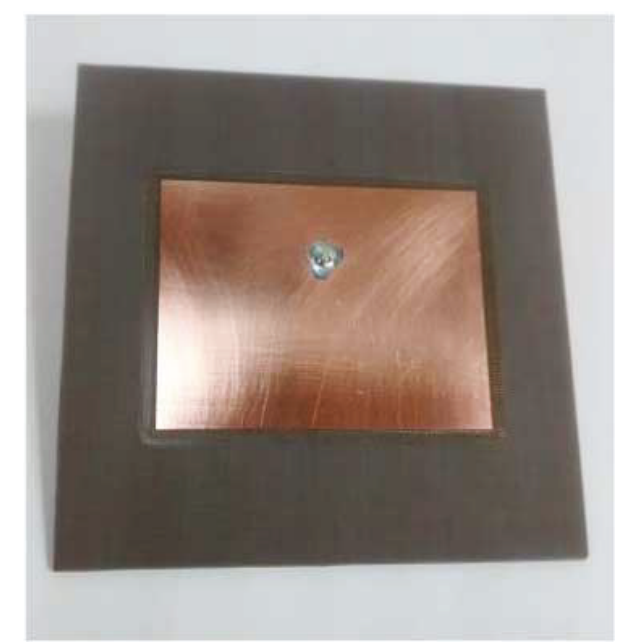

FIgURE 22: Conventional microstrip antenna prototype.

nominal value, specified as $\varepsilon_{r}=2.55 \pm 0.04$. To check this hypothesis, a conventional, linearly polarized rectangular microstrip antenna, fed by a $50 \Omega$ SMA connector, was designed to operate at $2.45 \mathrm{GHz}$ and manufactured from the same PCB lot (Figure 22).

This design option was based on ease of construction and numerous previous successful implementations. From HFSS simulation, the following dimensions resulted the following: $a=40 \mathrm{~mm}, b=52 \mathrm{~mm}$, and $p=12.45 \mathrm{~mm}$. Simulated and experimental results for the input impedance and the reflection coefficient module of the conventional antenna are presented in Figures 23 and 24.

As noticed in this simple case, the resonant frequency of the prototype antenna is still $16 \mathrm{MHz}$ below the expected HFSS simulation, thus confirming the hypothesis on permittivity variation. Since the resonant frequency shifted down, the actual permittivity of the laminate is greater than 2.55. Further HFSS simulation for a range of $\varepsilon_{r}$ values closed on 2.583, as pictured in Figures 23 and 24. 


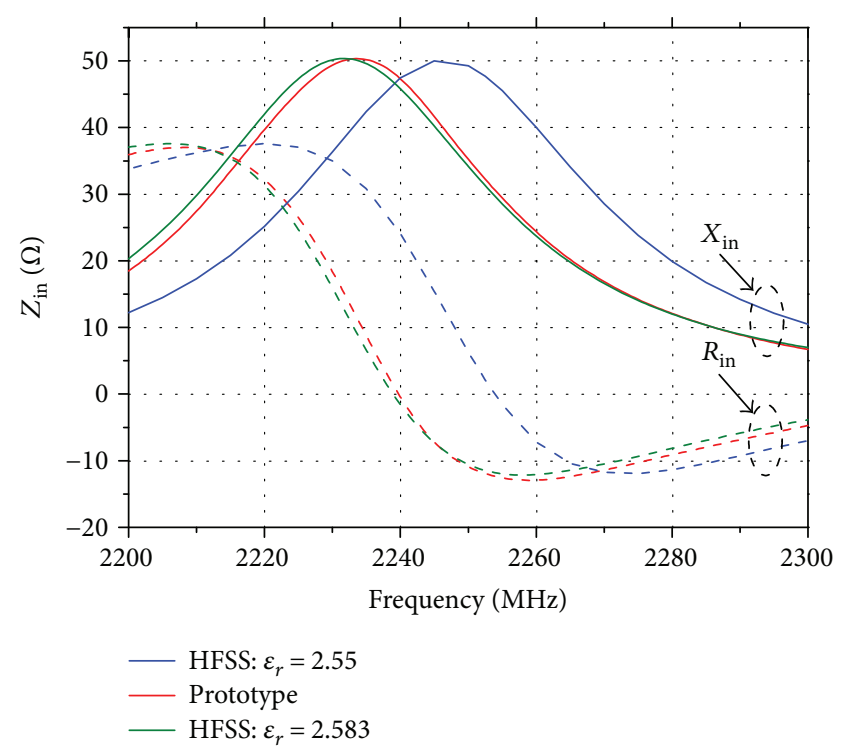

FIGURE 23: Input impedance of the conventional microstrip antenna.

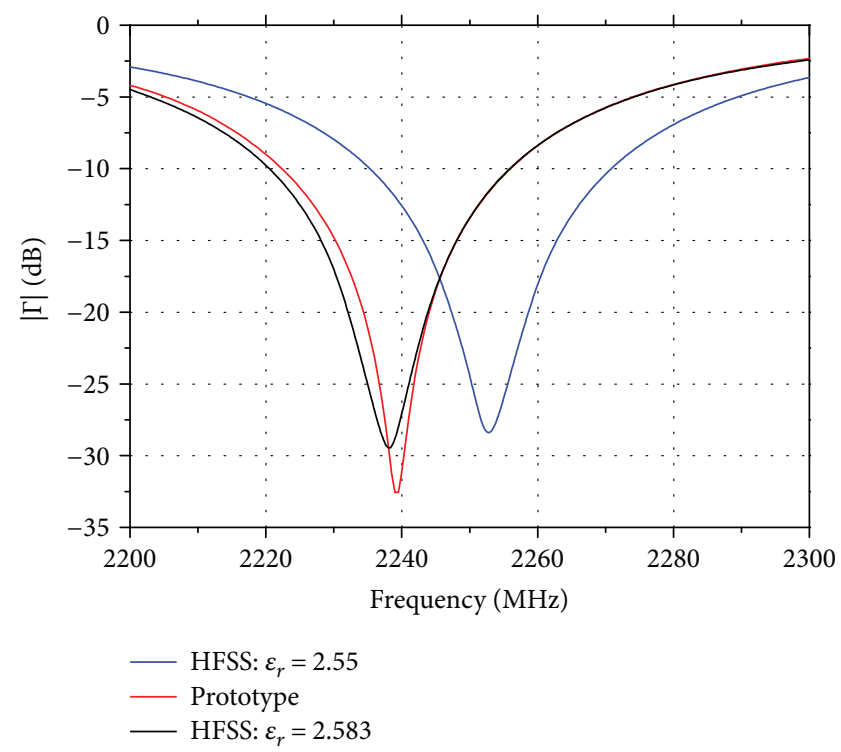

FIGURE 24: Reflection coefficient module of the conventional microstrip antenna.

Having confirmed the cause of the shift, the SIW antenna was simulated again, but now for $\varepsilon_{r}=2.583$. Results for the input impedance and the reflection coefficient module are presented in Figures 25 and 26. This time, an excellent match between the simulated and experimental results is observed.

Radiation patterns in the $E$ and $H$ planes at $2.434 \mathrm{GHz}$ are presented in Figures 27 and 28. As noticed, experimental and HFSS co-pol patterns on the $E$ and $H$ planes show a good match. Simulated cross-pol patterns are not plotted since they are below $-40 \mathrm{~dB}$. The higher level of the measured cross-polarization patterns relative to their simulation can be traced to the lack of a balun for the antenna under test. Results are good regardless, as expected for hybrid antennas.

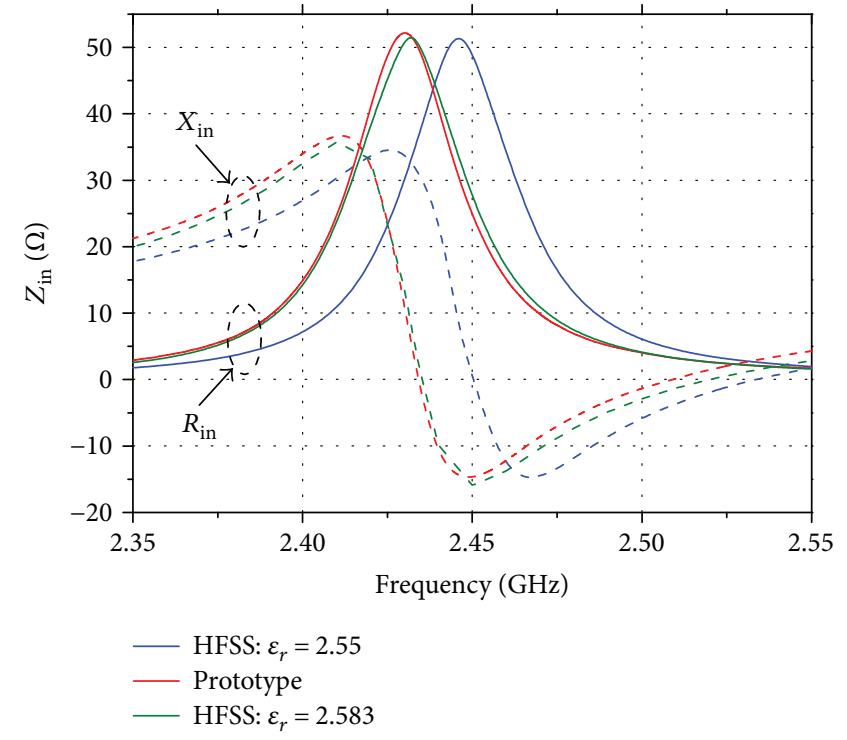

FIgURE 25: Input impedance of the SIW antenna.

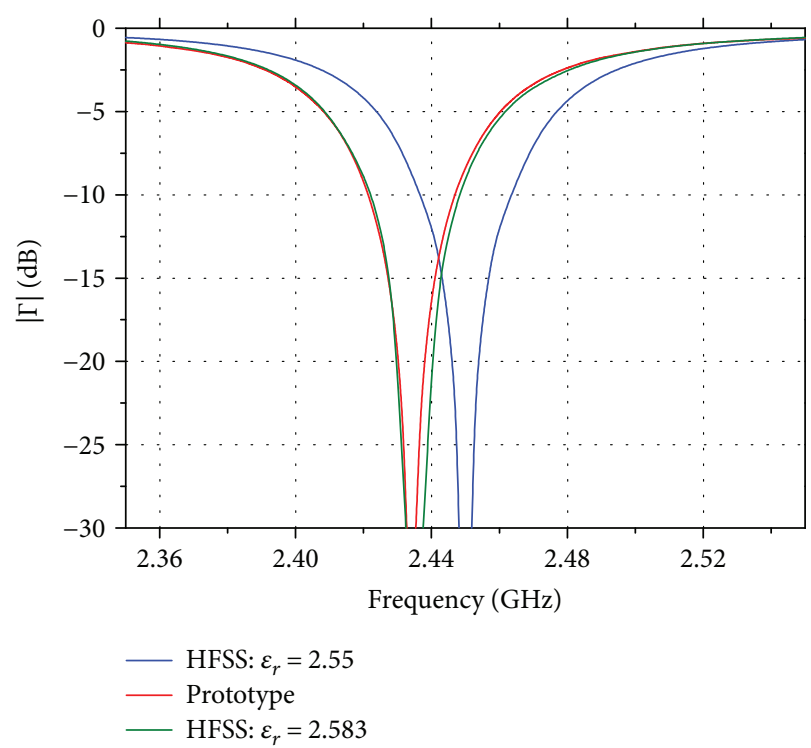

FIGURE 26: Reflection coefficient module of the SIW antenna.

\section{Final Comments}

An efficient procedure based on the equivalent resonant cavity model for fast and accurate predesign of probe-fed hybrid microstrip antennas is proposed in this article. This procedure, implemented in Mathematica in a straightforward way, has provided a comprehensive understanding of the effect of the electrical and geometrical parameters involved in the antenna analysis and synthesis, thus becoming a powerful tool for educational purposes. The proposed design criteria were focused on establishing an operation equivalent to the conventional antenna, but now with uniform radiation patterns in all planes, that is, balanced $3 \mathrm{~dB}$ angles. Besides, as the antenna is fed by a $50 \Omega$ SMA connector, the zero input null reactance condition was used for proper impedance 


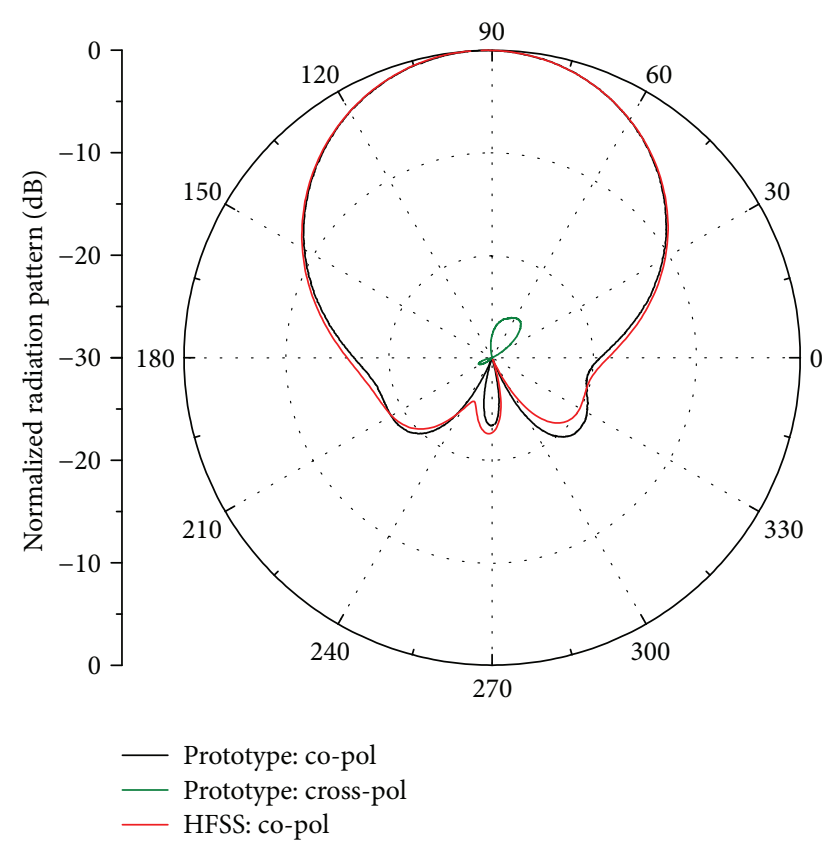

Figure 27: Normalized $E$ plane radiation pattern.

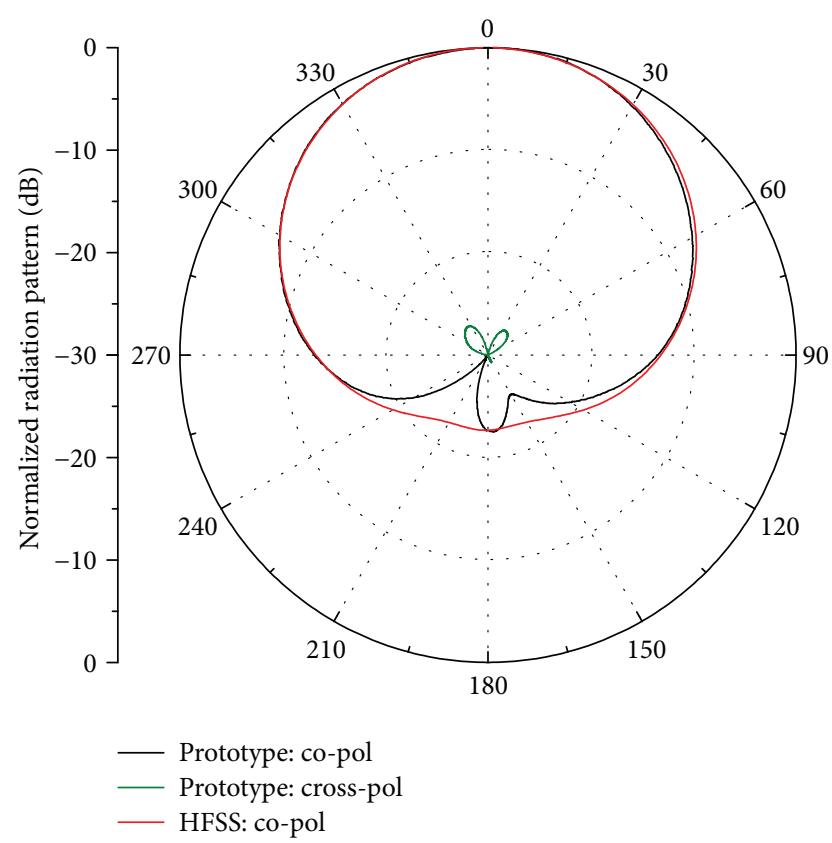

FIGURE 28: Normalized $H$ plane radiation pattern.

matching, resulting in a symmetrical bandwidth around the design frequency. Moreover, according to the rectangular coordinate system adopted, the $E_{\theta}$ component directly defines the copolarization of the hybrid antenna, whereas the cross-polarization is given by $E_{\phi}$, thus facilitating their analysis in $3 \mathrm{D}$ patterns. Additionally, the asymmetry of the $E$ plane radiation pattern was addressed, indicating that the lower the antenna input impedance is, the more asymmetrical the $E$ plane pattern will be. Finally, it is important to notice that, differently from their conventional counterparts, hybrid microstrip antennas fed by coaxial probes exhibit low cross-polarization level in the $\mathrm{H}$ plane.

Predesign results obtained with the proposed model for the hybrid radiator closely matched HFSS simulations, as well as actual measurements in a prototype that was built and tested. The excellent agreement validates the use of the cavity model for predesigning hybrid microstrip antennas in a simple, accurate, and time- and cost-effective way.

Since the practical implementation of vertical electric walls in microstrip structures is not an easy task, the SIW technique was used in the manufacturing of the prototype antenna, showing very good results.

\section{Conflicts of Interest}

The authors declare that they have no conflicts of interest.

\section{Acknowledgments}

The authors are grateful to FAPESP and CNPq for sponsoring Projects 2012/22913-5 and 402017/2013-7, respectively, and to IFI-DCTA for providing the anechoic chamber.

\section{References}

[1] CST, "Product overview," http://www.cst.com.

[2] HFSS, "Product overview," https://www.ansys.com/products/ electronics/ansys-hfss.

[3] G. A. Deschamps, "Microstrip microwave antennas," in The Third USAR Symposium on Antennas Research and Development Program, vol. 1, pp. 189-195, University of Illinois, Monticello, IL, USA, 1953.

[4] "Special Issue on Microstrip Antennas," IEEE Transactions on Antennas and Propagation, vol. 29, 1981.

[5] S. Bhardwaj and Y. Rahmat-Samii, "Revisiting the generation of cross-polarization in rectangular patch antennas: a near field approach," IEEE Antennas and Propagation Magazine, vol. 56, no. 1, pp. 14-38, 2014.

[6] P. Bhartia, K. V. S. Rao, and R. S. Tomar, Millimeter-Wave Microstrip and Printed Circuit Antennas, Artech House, Norwood, MA, USA, 1991.

[7] R. Garg, P. Bhartia, I. Bahl, and A. Ittipiboon, Microstrip Antenna Design Handbook, Artech House, Norwood, MA, USA, 2001.

[8] J. L. Volakis, Ed., Antenna Engineering Handbook, McGrawHill, New York, NY, USA, 4th edition, 2007.

[9] D. C. Nascimento, P. C. Ribeiro Filho, A. F. Tinoco-S, and J. C. S. Lacava, "Analysis and design of cavity-backed probefed hybrid microstrip antennas on FR4 substrate," International Journal of Antennas and Propagation, vol. 2015, Article ID 206967, 12 pages, 2015.

[10] H. Pues and A. Van de Capelle, "Accurate transmission-line model for the rectangular microstrip antenna," IEE Proceedings $H$ - Microwaves, Optics and Antennas, vol. 131, no. 6, pp. 334-340, 1984.

[11] W. F. Richards and Y. T. Lo, "An improved theory for microstrip antennas and applications," in Antennas and Propagation Society International Symposium, 1979, vol. 29no. 1, pp. 38-46, Seattle, WA, USA, Jan. 1979.

[12] P. Perlmutter, S. Strikman, and D. Treves, "Electric surface current model for the analysis of microstrip antennas with 
application to rectangular elements," IEEE Transactions on Antennas and Propagation, vol. 33, no. 3, pp. 301-311, 1985.

[13] A. F. Tinoco-S, M. V. T. Heckler, R. Schildberg, and J. C. S. Lacava, "Cylindrical: an effective CAD package for designing probe-fed rectangular microstrip antennas conformed onto cylindrical structures," IEEE Antennas and Propagation Magazine, vol. 50, no. 1, pp. 164-169, 2008.

[14] D. B. Ferreira and J. C. S. Lacava, "An efficient approach to the analysis and synthesis of spherical-circular thin microstrip antennas," in 2010 IEEE Antennas and Propagation Society International Symposium, pp. 1-4, Toronto, ON, Canada, July 2010.

[15] A. F. Tinoco-S, D. C. Nascimento, R. Schildberg, and J. C. S. Lacava, "Analysis and design of rectangular microstrip antennas for educational purposes," IEEE Antennas and Propagation Magazine, vol. 53, no. 1, pp. 151-155, 2011.

[16] P. C. Ribeiro Filho, D. C. Nascimento, A. F. Tinoco-S, and J. C. S. Lacava, "Design of flush-mounted hybrid microstrip antennas," in 2013 SBMO/IEEE MTT-S International Microwave \& Optoelectronics Conference (IMOC), pp. 1-5, Rio de Janeiro, Brazil, Aug. 2013.

[17] D. C. Nascimento and J. C. S. Lacava, "Cavity-backed hybrid microstrip antenna on FR4 substrate," in 2013 IEEE Antennas and Propagation Society International Symposium (APSURSI), pp. 166-167, Orlando, FL, USA, 2013.

[18] D. Ghosh, S. K. Ghosh, S. Chattopadhyay et al., "Physical and quantitative analysis of compact rectangular microstrip antenna with shorted non-radiating edges for reduced crosspolarization radiation using modified cavity model," IEEE Antennas and Propagation Magazine, vol. 56, no. 4, pp. 6172, 2014.

[19] Y. Luo and J. Bornemann, "Circularly polarized substrate integrated waveguide antenna with wide axial-ratio beamwidth," IEEE Antennas and Wireless Propagation Letters, vol. 16, pp. 266-269, 2017.

[20] F. Ren, W. Hong, and K. Wu, "W-band series-connected patches antenna for multibeam applications based on SIW Butler matrix," in 2017 11th European Conference on Antennas and Propagation (EUCAP), pp. 198-201, Paris, France, 19-24 Mar. 2017.

[21] Z. C. Hao, K. K. Fan, and H. Wang, “A planar polarizationreconfigurable antenna," IEEE Transactions on Antennas and Propagation, vol. 65, no. 4, pp. 1624-1632, 2017.

[22] D. C. Nascimento, Microstrip Antenna Arrays on Thick Substrates with Control of Main Beam Direction, Side Lobe Level, and Directivity, [Ph.D. Thesis], Technological Institute of Aeronautics, Brazil, 2013.

[23] E. Penard and J. P. Daniel, "Open and hybrid microstrip antenna," IEE Proceedings H Microwaves, Optics and Antennas, vol. 131, no. 1, pp. 38-44, 1984.

[24] M. H. A. Hassan, Design and Analysis of Substrate-Integrated Cavity-Backed Antenna Arrays for Ku-Band Applications, [Ph.D. Thesis], University of Tennessee, Knoxville, TN, USA, 2011.

[25] P. C. Ribeiro Filho, A. F. Tinoco-S, D. C. Nascimento, and J. C. S. Lacava, "Probe-fed hybrid-patch cylindrical SIW antenna," in 2014 IEEE Antennas and Propagation Society International Symposium (APSURSI), pp. 1714-1715, Memphis, TN, USA, July 2014.

[26] P. C. Ribeiro Filho, A. F. Tinoco-S, D. C. Nascimento, and J. C. S. Lacava, "Circumferential array of cylindrical hybrid antennas," in 2015 9th European Conference on Antennas and Propagation (EuCAP), Lisbon, Portugal, April 2015.

[27] Y. T. Lo, D. Solomon, and W. F. Richards, "Theory and experiment of microstrip antennas," IEEE Transactions on Antennas and Propagation, vol. 27, no. 2, pp. 137-145, 1979.

[28] N. R. Rabelo, Spectral Fields in Multilayer Structures Excited by Embedded Sources, [Ph.D. Thesis], Technological Institute of Aeronautics, Brazil, 2015.

[29] Mathematica, "Wolfram research product overview," http:// www.wolfram.com/.

[30] E. O. Hammerstad, "Equations for microstrip circuit design," in 1975 5th European Microwave Conference, pp. 268-272, Hamburg, Germany, September 1975.

[31] D. C. Nascimento and J. C. S. Lacava, "Design of low-cost probe-fed microstrip antennas," in Microstrip Antennas, Chapter 01, N. Nasimuddin, Ed., InTech, 2011.

[32] Y. J. Cheng, Substrate Integrated Antennas and Arrays, CRC Press, Boca Raton, FL, USA, 2015. 


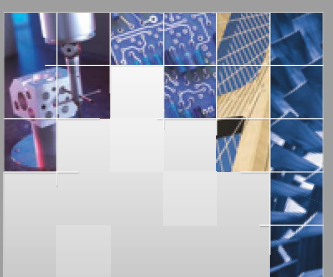

\section{Enfincering}
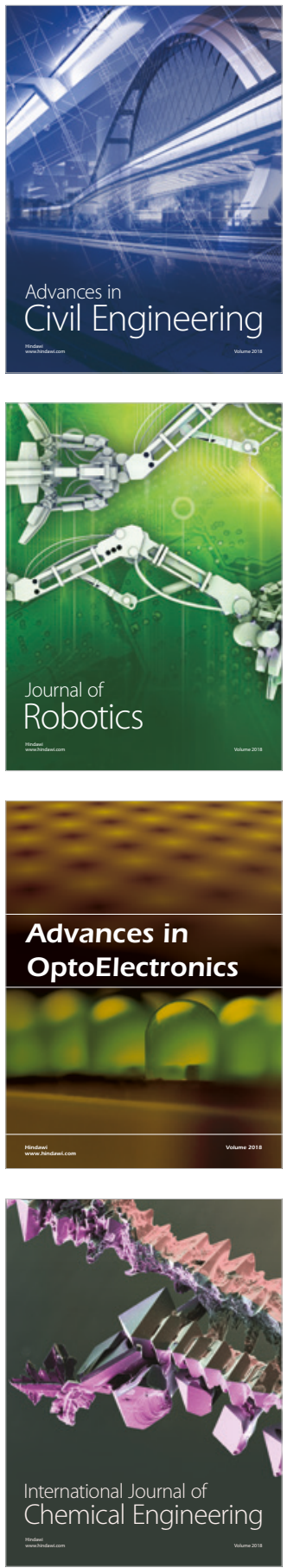

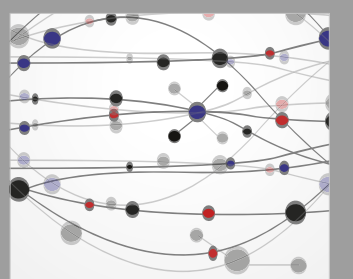

\section{Rotating \\ Machinery}

The Scientific World Journal

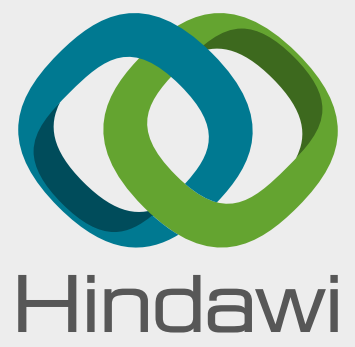

Submit your manuscripts at

www.hindawi.com
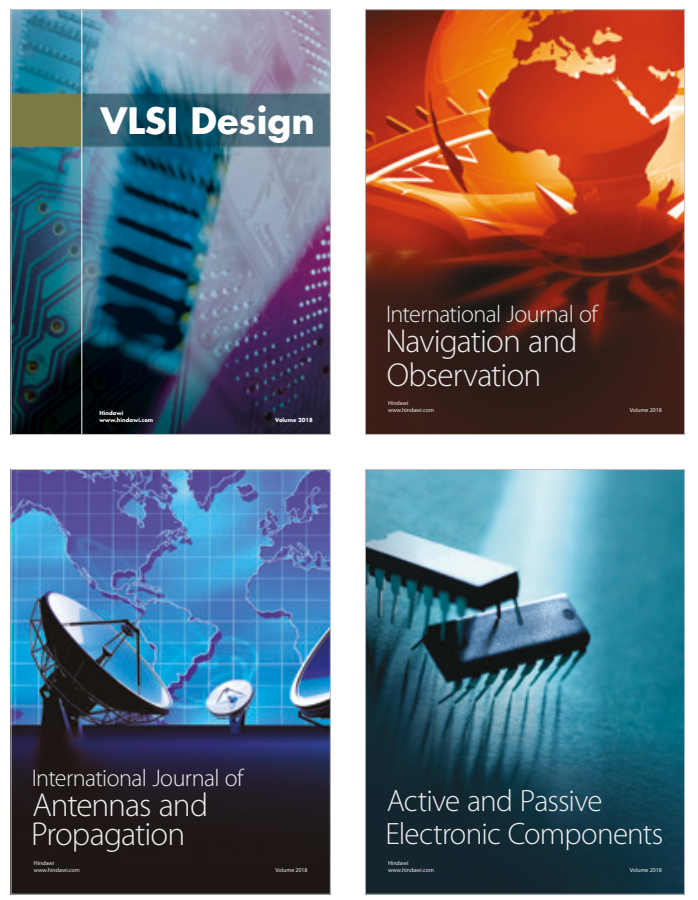
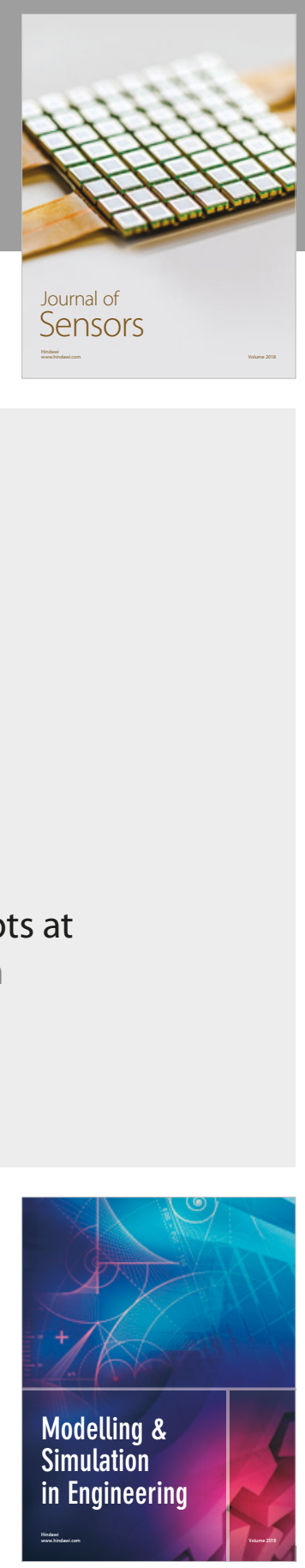

\section{Advances \\ Multimedia}
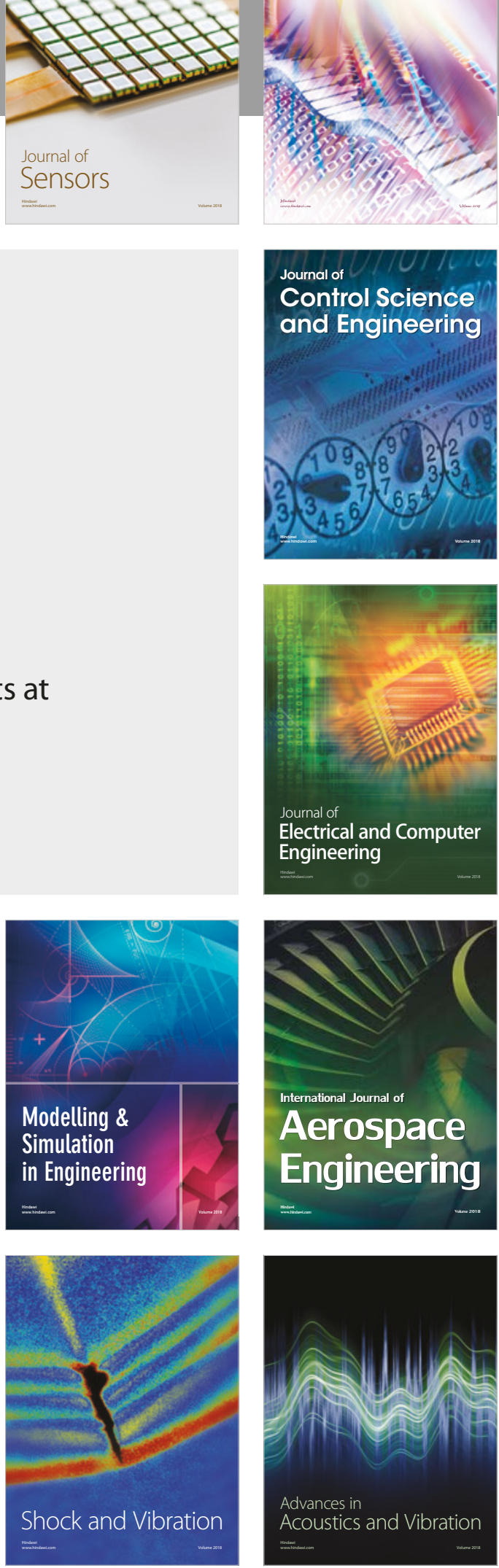